\title{
A New Algorithm for the Available Transfer Capability Determination
}

\author{
Stendley Busan, ${ }^{1}$ Muhammad Murtadha Othman, ${ }^{1,2}$ \\ Ismail Musirin, ${ }^{1}$ Azah Mohamed, ${ }^{3}$ and Aini Hussain ${ }^{3}$ \\ ${ }^{1}$ Faculty of Electrical Engineering, MARA University of Technology, Shah Alam, \\ 40450 Selangor, Malaysia \\ ${ }^{2}$ Centre of Electrical Power Engineering Studies, MARA University of Technology, Shah Alam, \\ 40450 Selangor, Malaysia \\ ${ }^{3}$ Department of Electrical, Electronic and Systems Engineering, Faculty of Engineering, \\ National University of Malaysia (UKM), Bangi, 43600 Selangor, Malaysia \\ Correspondence should be addressed to Muhammad Murtadha Othman, \\ mamat505my@yahoo.com
}

Received 19 November 2009; Accepted 9 June 2010

Academic Editor: Alois Steindl

Copyright (C) 2010 Stendley Busan et al. This is an open access article distributed under the Creative Commons Attribution License, which permits unrestricted use, distribution, and reproduction in any medium, provided the original work is properly cited.

\begin{abstract}
This paper presents a fast and accurate method to determine the available transfer capability. Ralston's method is used to predict the two trajectory points of voltage magnitude, power flow, and maximum generator rotor angle difference. Then, the cubic spline interpolation technique is used to accurately trace the $P-V, P-S$, or $P-\Delta \delta$ curves between two points of trajectory. The $P-V, P-S$ and $P$ $\Delta \delta$ curves represent as the variations of voltage magnitude, power, flow and maximum generator rotor angle difference due to the increase of power transfer. The actual available transfer capability value is determined at the intersection point between the curve and the constraints limit. The effectiveness of the proposed method is verified by referring to the results of ATC for a case study of 2737-Polish system and 39-New England bus system. The proposed method gives satisfactorily accurate and fast computation of ATC as compared to recursive AC power flow method.
\end{abstract}

\section{Introduction}

Transferring an electric power from one place to another is an alternative way to provide effective electric power required by the demand. This may assist towards reduction in a system operational cost. Nowadays, the power trade activity which is involved in the wholesale power market requires accurate information of power transfer between areas. Such vital information can help power marketers, sellers, and buyers in planning, operation, and reserving transmission services [1]. There are two significant indices in the transfer capability assessment, namely, the total transfer capability (TTC) and the available transfer capability 
(ATC). TTC represents as the maximum amount of power that can be transferred over the interconnected transmission network in a reliable manner while meeting all of a specific set of defined pre- and postcontingency system conditions [2]. On the other hand, ATC is a measure of the additional amount of power that flows across the interface, over and above the base case flows without jeopardizing power system security [3].

The determination of ATC for a large and complex power system usually utilizes excessive amount of computational time. This instigates to a new development of a fast and accurate method in determining the ATC value. Various approaches have been proposed to determine ATC such as using the methods of DC power flow [1], AC power flow [4], optimal power flow [5], sensitivity [6], curve fitting-based cubic spline interpolation technique [7], and artificial neural network [8]. The method based on linear DC power flow considering distribution factors is considered fast but less accurate for transfer capability analysis because the DC network model does not require the voltage magnitude and reactive power component in the power flow calculation. Therefore, the computation is based on the linear DC power flow resulting in an inaccurate ATC value, especially for the heavily stressed system that is caused by critical contingencies. The AC power flow method gives an accurate solution in determining the ATC because it considers the effects of reactive power flows and voltage limits. However, transfer capability evaluation using repetitive AC power flows is time consuming because it requires a load flow solution at every transfer step size. To avoid many repetitive AC power flow solutions, curve fitting technique such as cubic spline interpolation technique has been used [7]. There are various curve fitting techniques that are used for voltage stability analysis such as the least square fit of second-order polynomial [9], cubic spline interpolation [10] and quadratic approximation [11].

This paper proposes a new approach to determine fast and accurate value of ATC by using Ralston's method incorporating with cubic spline interpolation technique. The Ralston's method is categorized under the second-order Runge-Kutta method and this is similar to Heun's and midpoint methods. However, the Ralston's method is superior to Heun's and midpoint methods in terms of providing a minimum bound of truncation error in extrapolation [12]. The Ralston's method is used to determine the two trajectory points of voltage magnitude, power flow, or maximum generator rotor angle difference. Then, the cubic-spline interpolation technique is used to accurately trace the $P-V, P-S$, or $P-\Delta \delta$ curves between the two trajectory points of voltage magnitude $(V)$, power flow $(S)$, or maximum generator rotor angle difference $(\Delta \delta)$, respectively. The $P-V, P-S$ and $P-\Delta \delta$ curves represent as the variations of voltage magnitude, power flow, and maximum generator rotor angle difference due to the increase of power transfer, respectively. The ATC is then determined at a point when the voltage magnitude limit, power flow limit or generator rotor angle difference limit intersects the curve. In the ATC estimation, the transmission line and voltage magnitude limits are considered as the steady-state security constraints whereas the maximum generator angle difference limit is referred to as the transient stability constraint. The transfer capability of a system is analyzed under two different sets of transfer, which are the area-to-area ATC and point-to-point ATC. Area-to-area ATC is the additional amount of power transferred from the selling area to the buying area without jeopardizing the system security. On the other hand, point-to-point ATC is the additional amount of power transferred from the selling bus to the buying bus without violating the system security. The effectiveness of the proposed method in estimating fast and accurate computation of ATC is verified on the case studies of 2737-bus Polish system [13] and 39-New England bus system. The proposed method can be used in the probabilistic assessment of transfer capability. This is due to the fact that the proposed method is able to accurately determine the ATC in a less computational time for 
every system operating condition. The system operating conditions such as the transmission line failures are usually generated by the Monte Carlo simulation technique or parametric bootstrap technique. The ATCs are then used in the probabilistic based risk or uncertain assessment of transfer capability.

\section{Problem Formulation}

The first section describes the problem definition of ATC followed by the explanation of Ralston's method that is used to determine the two trajectory points of voltage magnitude, power flow, and maximum generator rotor angle difference. The last section provides a detailed explanation of cubic spline formulation that is used for tracing the $P-V, P-S$, and $P-\Delta \delta$ curves between the two trajectory points for accurate ATC determination.

\subsection{ATC Problem Definition}

ATC is defined as the TTC less than the transmission reliability margin (TRM), less than the sum of existing transmission commitments (ETCs), and capacity benefit margin (CBM) $[2,14,15]$. The TRM is the amount of transmission capability necessary to ensure that the interconnected system is secure under a reasonable range of uncertainties in system conditions. The CBM is the amount of transmission transfer capability reserved by load serving entities to ensure access to generation from interconnected systems to meet generation reliability requirements. The ETC is the normal transmission flows included in the given case. The methods to determine the TRM, CBM, and ETC margins may vary among regions, power pools, individual system, and load-serving entities.

ATC must satisfy certain principles balancing both technical and commercial issues, so that the interconnected transmission network is performed based on the commercial requirements associated with transmission service requests. The following principles identify the requirements for the calculation and application of ATC.

(a) Electricity demand and supply cannot be treated independently of one another. All system conditions must be considered to accurately access the capabilities of the transmission network.

(b) Electric power flows resulting from each power transfer use the entire network and are not governed by the commercial terms of the transfer.

(c) ATC calculations must use a regional or wide-area approach to capture the interactions of electric power flows among individual, regional, subregional, and multiregional systems.

(d) The determination of ATC must accommodate reasonable uncertainties in system conditions and provide operating flexibility to ensure a secure operation of the interconnected network.

In the determination of ATC, the transmission lines flow and voltage magnitudes limits have to be taken into account in the calculation. All these limits can be handled by the AC load flow power system model. Limits due to transient or oscillations are not often addressed in the ATC determination because these limits are crudely approximated by flow limits [16]. However, the large disturbance such as system faults, loss of generator, or equipment outages could lead to undesirable behavior that affects the stability of a system. 
The undesirable behavior is associated with the transient stability which could lead to great losses and costly to the utilities. Therefore, it is necessary to consider the transient stability constraints within the ATC calculation.

\subsection{Formulation of Ralston's Method}

A generic ATC computation is performed by solving recursive AC power flow calculations due to the increased amount of power transfers between areas or buses. The ATC is then determined by referring to the increase amount of power transfer caused to the violation of a system constraint such as the voltage magnitude limit, transmission line limit or generator rotor angle difference limit. In the ATC computation using the recursive AC power flow solution, the variations of voltage magnitude $(V)$, MVA power flow $(S)$, and maximum generator rotor angle difference $(\Delta \delta)$ due to the increase of MW power transfers $(P)$ can be described in terms of $P-V, P-S$, and $P-\Delta \delta$ curves, respectively. By considering the $P-V, P-S$ and $P-\Delta \delta$ curves as the quadratic polynomial form, Ralston's method can be used to approximate the two trajectory points of voltage magnitude, power flow, and maximum generator rotor angle difference. Then, the cubic-spline interpolation technique is used to accurately trace the $P-V, P-S$, or $P-\Delta \delta$ curves between the two specific points of trajectory. The proposed methodology is able to provide accurate value of ATC by taking into account the steady-state and transient stability constraints.

The Ralston's method is used to approximate the two trajectory points of voltage magnitude, power flow, and maximum generator rotor angle difference [12], and it is derived from a basic extrapolation equation that is given by (2.1)

$$
y_{n+1}=y_{n}+\phi h
$$

Equation (2.1) represents that the $\phi$ is used to extrapolate from an old value of $y_{n}$ to a new value of $y_{n+1}$ over a distance of $h$. The second order of (2.1) gives

$$
y_{n+1}=y_{n}+\left(a_{1} s_{1}+a_{2} s_{2}\right) h
$$

where

$$
\begin{gathered}
s_{1}=f\left(x_{n}, y_{n}\right), \\
s_{2}=f\left(x_{n}+p h, y_{n}+q s_{1} h\right) .
\end{gathered}
$$

The $a_{1}, a_{2}, p$, and $q$ are the unknown constants used to satisfy the three conditions

$$
\begin{gathered}
a_{1}+a_{2}=1, \\
a_{2} p=\frac{1}{2}, \\
a_{2} q=\frac{1}{2} .
\end{gathered}
$$


By referring to (2.2a), the value of $a_{2}$ is assumed to be $2 / 3$ thus resulting in the values of $a_{1}=1 / 3$ and $p=q=3 / 4$. This yields to a Ralston's method given by (2.3).

$$
y_{n+1}=y_{n}+\left(\frac{1}{3} s_{1}+\frac{2}{3} s_{2}\right) h,
$$

where,

$$
\begin{gathered}
s_{1}=f\left(x_{n}, y_{n}\right), \\
s_{2}=f\left(x_{n}+\frac{3}{4} h, y_{n} \frac{3}{4} s_{1} h\right) .
\end{gathered}
$$

Note that $x$ is equivalent to the power transfer, $P$. It is worth mentioning that the Ralston's method given in (2.3) is used to extrapolate the second-order polynomial curvature. The second-order polynomial is represented by

$$
y=\alpha+\beta P+\gamma P^{2}
$$

The first order of (2.5) yields (2.6a) and it is representing as $s_{1}$,

$$
\frac{d y}{d x}=\beta+2 \gamma P_{n}
$$

Thus, $s_{1}$ in $(2.4 \mathrm{a})$ is given by

$$
s_{1}=\beta+2 \gamma P_{n}
$$

By applying (2.6a) into (2.4b),

$$
s_{2}=\beta+2 \gamma\left(P_{n}+\frac{3}{4} h\right)
$$

The value of constants $\beta$ and $\gamma$ can be determined by using the least square method [12]. The step size, $h$, of power transfer is determined as below,

$$
h=\frac{P_{\text {look }}+P_{1}}{n}
$$

where $n$ is the number of incremental steps for power transfer. In this case study, $n$, is specified as 4 in which it is reasonable enough to provide accurate approximation of the two trajectory points. $P_{1}$ is the initial power transfer that is $1 \mathrm{MW}$. $P_{\text {look }}$ is the look-ahead power transfer which may cause the violation of voltage, transmission line, or generator rotor angle difference limits. The methodology of look-ahead power transfer is explained elaborately in Section 3. 
The next power transfer, $P_{n+1}$, for each $n$th incremental step is determined by using.

$$
P_{n+1}=P_{n}+h
$$

The values obtained from (2.6b), (2.6c), (2.6d), and (2.7a) are used in (2.3) so that the Ralston's method could perform the extrapolation in order to obtain the two points of trajectory. The value of $y$ that is obtained from (2.3) represents as the voltage magnitude, power flow, or maximum generator rotor angle difference. The $P_{n}$ is increased at each $n$th incremental step by using (2.7a) until the Ralston's method in (2.3) gives $y$ value that violates the system constraint. The last two values of $y$ represent as the two trajectory points of voltage magnitude, power flow, or maximum generator rotor angle difference. It is then used in the cubic-spline interpolation technique to accurately trace the $P-V, P-S$ or $P-\Delta \delta$ curves.

It is obvious that the step size, $h$, of power transfer given in (2.6d) is highly dependent on the number of incremental steps, $n$. A reasonable number of incremental steps, $n$, need to be specified so that the Ralston's method in (2.3) could perform the extrapolation with a minimum computational time. The number of incremental steps, $n$, is specified under two categories. First, a large number of incremental steps, $n$, may cause a lengthy computational time in the extrapolation process due to a small step size, $h$. Second, a small number of incremental steps, $n$, yield a fast computational time in the extrapolation process due to a large step size, $h$. In this case study, four incremental steps $(n)$ are used, and it is reasonable enough for the Ralston's method to provide fast and accurate approximation of the two trajectory points. Furthermore, the cubic-spline interpolation technique is used to accurately trace the curve between the two trajectory points with a large value of step size, $h$, and this will be discussed in the next subsection.

\subsection{Cubic-Spline Interpolation Technique}

The methodology of cubic-spline interpolation technique is basically based on determining the four known points and then fitting appropriate curves to the four points. In the cubicspline technique [7], tracing the curves $f\left(k_{1}\right), f\left(k_{2}\right)$, and $f\left(k_{3}\right)$ begins with finding the value for parameters $f^{\prime \prime}\left(x_{2}\right), f^{\prime \prime}\left(x_{3}\right)$, and $f^{\prime \prime}\left(x_{4}\right)$ which are given as

$$
\begin{aligned}
f^{\prime \prime}\left(x_{2}\right)= & \left\{2\left(\frac{x_{4}-x_{2}}{x_{3}-x_{2}}\right)\left[\frac{6}{x_{3}-x_{2}}\left[f\left(x_{3}\right)-f\left(x_{2}\right)\right]+\frac{6}{x_{2}-x_{1}}\left[f\left(x_{1}\right)+f\left(x_{2}\right)\right]\right]\right. \\
& \left.-\frac{6}{x_{4}-x_{3}}\left[f\left(x_{4}\right)-f\left(x_{3}\right)\right]+\frac{6}{x_{3}-x_{2}}\left[f\left(x_{2}\right)+f\left(x_{3}\right)\right]\right\} \\
\div & \left\{2\left(x_{3}-x_{1}\right) * 2\left(\frac{x_{4}-x_{2}}{x_{3}-x_{2}}\right)-\left(x_{3}-x_{2}\right)\right\}, \\
f^{\prime \prime}\left(x_{3}\right)= & \left\{\frac{6}{x_{4}-x_{3}}\left[f\left(x_{4}\right)-f\left(x_{3}\right)\right]+\frac{6}{x_{3}-x_{2}}\left[f\left(x_{2}\right)-f\left(x_{3}\right)\right]\right. \\
& \left.-\left[\left(x_{3}-x_{2}\right) * f^{\prime \prime}\left(x_{2}\right)\right]\right\} \div 2\left(x_{4}-x_{2}\right),
\end{aligned}
$$




$$
\begin{aligned}
f^{\prime \prime}\left(x_{4}\right)= & \left\{\frac{6}{x_{4}-x_{3}}\left[f\left(x_{4}\right)-f\left(x_{3}\right)\right]+\frac{6}{x_{3}-x_{2}}\left[f\left(x_{2}\right)-f\left(x_{3}\right)\right]\right. \\
& \left.-\left[\left(x_{3}-x_{2}\right) * f^{\prime \prime}\left(x_{2}\right)\right]-\left[2\left(x_{4}-x_{2}\right) * f^{\prime \prime}\left(x_{3}\right)\right]\right\} \div\left(x_{4}-x_{2}\right) .
\end{aligned}
$$

The values for parameters $f^{\prime \prime}\left(x_{2}\right), f^{\prime \prime}\left(x_{3}\right)$, and $f^{\prime \prime}\left(x_{4}\right)$ are used in the cubic-spline equations in order to obtain the curve functions of $f\left(k_{1}\right), f\left(k_{2}\right)$, and $f\left(k_{3}\right)$, which are given as,

$$
\begin{aligned}
f\left(k_{1}\right)= & \frac{f^{\prime \prime}\left(x_{2}\right)}{6\left(x_{2}-x_{1}\right)}\left(k_{1}-x_{1}\right)^{3}+\frac{f\left(x_{1}\right)}{x_{2}-x_{1}}\left(x_{2}-k_{1}\right)+\frac{f\left(x_{2}\right)}{x_{2}-x_{1}}\left(k_{1}-x_{1}\right), \\
f\left(k_{2}\right)= & \frac{f^{\prime \prime}\left(x_{2}\right)}{6\left(x_{3}-x_{2}\right)}\left(x_{3}-k_{2}\right)^{3}+\frac{f^{\prime \prime}\left(x_{3}\right)}{6\left(x_{3}-x_{2}\right)}\left(k_{2}-x_{2}\right)^{3} \\
& +\left[\frac{f\left(x_{2}\right)}{x_{3}-x_{2}}-\frac{f^{\prime \prime}\left(x_{2}\right)\left(x_{3}-x_{2}\right)}{6}\right]\left(x_{3}-k_{2}\right) \\
& +\left[\frac{f\left(x_{3}\right)}{x_{3}-x_{2}}-\frac{f^{\prime \prime}\left(x_{2}\right)\left(x_{3}-x_{2}\right)}{6}\right]\left(k_{2}-x_{2}\right), \\
f\left(k_{3}\right)= & \frac{f^{\prime \prime}\left(x_{3}\right)}{6\left(x_{4}-x_{3}\right)}\left(x_{4}-k_{3}\right)^{3}+\frac{f^{\prime \prime}\left(x_{4}\right)}{6\left(x_{4}-x_{3}\right)}\left(k_{3}-x_{3}\right)^{3} \\
& +\left[\frac{f\left(x_{3}\right)}{x_{4}-x_{3}}-\frac{f^{\prime \prime}\left(x_{3}\right)\left(x_{4}-x_{3}\right)}{6}\right]\left(x_{4}-k_{3}\right) \\
& +\left[\frac{f\left(x_{4}\right)}{x_{4}-x_{3}}-\frac{f^{\prime \prime}\left(x_{3}\right)\left(x_{4}-x_{3}\right)}{6}\right]\left(k_{3}-x_{3}\right) .
\end{aligned}
$$

In the $P-V$ curve fitting, the parameters $f^{\prime \prime}\left(x_{2}\right), f^{\prime \prime}\left(x_{3}\right)$, and $f^{\prime \prime}\left(x_{4}\right)$ can be described as $V^{\prime \prime}\left(P_{2}\right), V^{\prime \prime}\left(P_{3}\right)$, and $V^{\prime \prime}\left(P_{4}\right)$, respectively. On the other hand, the parameters $f^{\prime \prime}\left(x_{2}\right), f^{\prime \prime}\left(x_{3}\right)$, and $f^{\prime \prime}\left(x_{4}\right)$ can also be described as $S^{\prime \prime}\left(P_{2}\right), S^{\prime \prime}\left(P_{3}\right)$, and $S^{\prime \prime}\left(P_{4}\right)$, respectively for the case of $P$ - $S$ curve fitting. For the case of $P-\Delta \delta$ curve fitting, the parameters $f^{\prime \prime}\left(x_{2}\right), f^{\prime \prime}\left(x_{3}\right)$, and $f^{\prime \prime}\left(x_{4}\right)$ can be described as $\Delta \delta^{\prime \prime}\left(P_{2}\right), \Delta \delta^{\prime \prime}\left(P_{3}\right)$, and $\Delta \delta^{\prime \prime}\left(P_{4}\right)$, respectively. $f\left(k_{l}\right)$ is the cubic-spline function that is used for tracing the curves of voltage magnitude, $V\left(k_{l}\right)$, MVA power flow, $S\left(k_{l}\right)$, and maximum generator rotor angle difference, $\Delta \delta\left(k_{l}\right) . k_{l}$ is the increase of power transfer by $1 \mathrm{MW}$ between $x_{l}$ and $x_{l+1} . l$ is the number of three incremental steps, that is, 1,2 , and 3 . Specifically, $f\left(k_{l}\right)$ is used for tracing the curves between the four points of $f\left(x_{n}\right)$ with respect to the increase of $k_{l}$ by $1 \mathrm{MW}$ from $x_{l}$ to $x_{l+1}$. Whereby, $f\left(x_{n}\right)$ represents as the four points of voltage magnitude, $V\left(P_{n}\right)$, MVA power flow, $S\left(P_{n}\right)$, or maximum generator rotor angle difference, $\Delta \delta\left(P_{n}\right)$, which are obtained from the AC power flow solutions. The four points of real power transfer, $x_{n}$, can also be described as $P_{n}$, where $n=1,2,3$, and 4 . For an example, the curve from point $f\left(x_{1}\right)$ to point $f\left(x_{2}\right)$ is traced by using $f\left(k_{1}\right)$ with the increase of $k_{1}$ by $1 \mathrm{MW}$ from $x_{1}=1 \mathrm{MW}$ to $x_{2}=300 \mathrm{MW}$. 


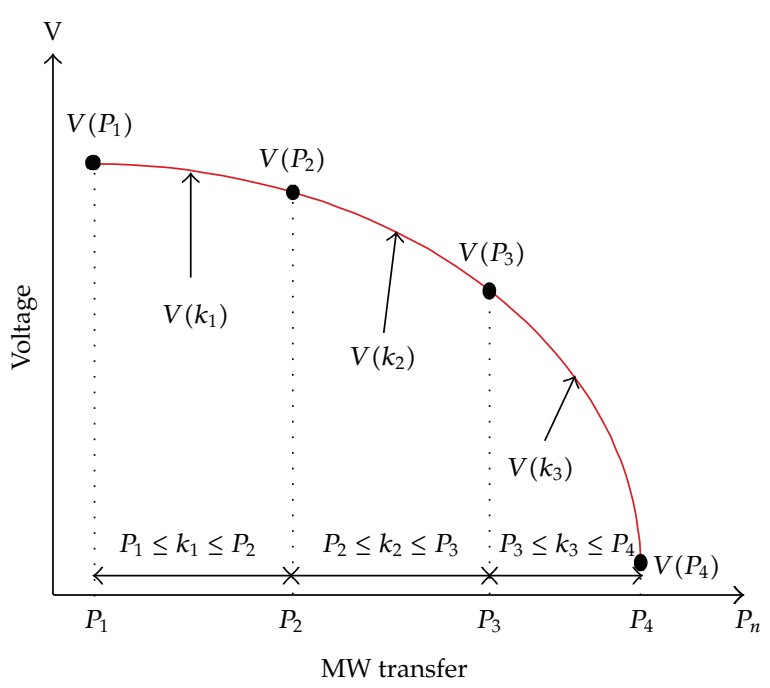

Figure 1: Illustration of cubic-spline technique used in tracing the $P-V$ curve.

\subsection{Determination of P-V, P-S, and P- $\Delta \delta$ Curves Using Cubic-Spline Interpolation Technique}

Generally, there are two main procedures involved in the $P$ - $V$ curve fitting using the cubicspline interpolation technique. First, the voltage at each point of real power transfer, $V\left(P_{n}\right)$, is obtained by solving the AC power flow solution. Second, the cubic-spline interpolation technique is used for tracing the voltage curves, $V\left(k_{l}\right)$, based on the four voltage points, $V\left(P_{n}\right)$, which are obtained from the previous four AC power flow solutions and this is shown in Figure 1. Particularly, the curve from point $V\left(P_{1}\right)$ to point $V\left(P_{2}\right)$ is traced by using $V\left(k_{1}\right)$ with the increase of $k_{1}$ by $1 \mathrm{MW}$ from $P_{1}$ to $P_{2}$. Then, the next curve from point $V\left(P_{2}\right)$ to point $V\left(P_{3}\right)$ is traced by using $V\left(k_{2}\right)$ with the increase of $k_{2}$ by $1 \mathrm{MW}$ from $P_{2}$ to $P_{3}$. Finally, the last curve from point $V\left(P_{3}\right)$ to point $V\left(P_{4}\right)$ is traced by using $V\left(k_{3}\right)$ with the increase of $k_{3}$ by $1 \mathrm{MW}$ from $P_{3}$ to $P_{4}$.

Similarly, the cubic-spline interpolation technique is used in tracing the $P$-S curves representing as the MVA power flow variations with respect to the increase of power transfer. The procedures that are used in tracing the curves $S\left(k_{1}\right), S\left(k_{2}\right)$ and $S\left(k_{3}\right)$ between the four points of MVA power flow $S\left(P_{n}\right)$ are similar to those described for tracing the voltage curves, except that the voltage variables in (2.8) to (2.11)are replaced by the MVA power flow variables. This is similar to a case whereby the cubic-spline interpolation technique is used for tracing the $P-\Delta \delta$ curves.

\subsection{Transient Stability Constraint}

In this study, the transient stability is obtained by analyzing the "first swing" of each generator. Transient stability is referred to as the generator rotor angle that is returning to its synchronism state after the fault is cleared. A classical model of a synchronous generator is used in this case of study, and the details can be accessed in [17]. The transient stability, based rotor angle is measured by referring to the difference between relative rotor angle, 
with respect to the center of inertia (COI) [18-20]. The transient stability limit should be less or equal to $180^{\circ}$, and it is given by

$$
\delta_{\mathrm{COI}}=\frac{\sum_{g=1}^{G} M_{g} \delta_{g}}{\sum_{g=1}^{G} M_{g}}, \quad\left[\left|\Delta \delta_{g}\right|=\delta_{g}-\delta_{\mathrm{COI}}\right] \leq 180^{\circ},
$$

where $\delta_{g}$ is rotor angle of $g$ th generator. $\Delta \delta_{g}$ is rotor angle difference of $g$ th generator. $M_{g}$ is generator inertia constant in seconds for $g$-th generator.

The maximum rotor angle difference for unstable condition is taken at the end of time simulation. This is due to the fact that the relative rotor angle is monotonically increasing if the generator losing its synchronism. On the other hand, for a stable condition, the maximum relative rotor angle is taken within the simulation time interval. This is because the increased relative rotor angle is returning back to its synchronism state after the fault is cleared.

\section{Procedure of ATC Evaluation Using Ralston's Method Incorporating Cubic-Spline Interpolation Technique}

Generally, the main steps involved in the transfer capability computation are the definition of a base case, determination of network response, and finding the maximum transfer or ATC. Determination of the area-to-area and point-to-point ATCs using the Ralston's method incorporating cubic-spline interpolation technique is described as follows.

(a) Establish a solved base case AC power flow solution.

(b) Specify the area or point of transfers. For the point-to-point transfer, a generator is considered as a selling bus and a load is a buying bus. However, the area-to-area transfer considers participation of all generators in the specified selling area and all loads in the specified buying area.

(c) Simultaneously, increase the power generation $\left(P_{\mathrm{Gn}}\right)$ and load $\left(P_{\mathrm{Dn}}\right)$ at the selected buses or areas at three incremental steps in order to obtain the variations of voltage $\left(V_{i, n}\right)$, the power flow $\left(S_{i j, n}\right)$ and maximum generator rotor angle difference $\left(\Delta \delta_{g, n}\right)$. Where, $i$ is the bus number, $i j$ is the transmission line connected between bus $i$ and bus $j$, and $g$ is the number of generator. The AC power flow solution should be performed for each incremental step of $P_{\mathrm{Gn}}$ and $P_{\mathrm{Dn}}$. The amount of power generation, $P_{\mathrm{Gn}}$ is equivalent to the amount of power transfer, $P_{n}$. Then, the sensitivity method is used to identify the sensitive bus, transmission line or generator that has the highest potential to be violated due to the increase amount of power transfer [21]. Equations (3.1), (3.2), (3.3) and (3.4) are the sensitivity methods that are used to approximate the amount of power transfer, $P$, corresponding to each bus, transmission line and generator. Then, the sensitive line, bus or generator is selected based on the minimum amount of power transfer:

$$
\begin{aligned}
& P_{i, \text { Vlower }}=P_{1}+\left|\left(\frac{P_{3}-P_{1}}{V_{i, 3}-V_{i, 1}}\right) \times\left(V_{\text {lower }}-V_{i, 1}\right)\right|, \\
& P_{i, \text { Vupper }}=P_{1}+\left|\left(\frac{P_{3}-P_{1}}{V_{i, 3}-V_{i, 1}}\right) \times\left(V_{\text {upper }}-V_{i, 1}\right)\right|,
\end{aligned}
$$




$$
\begin{gathered}
P_{i j, S}=P_{1}+\left|\left(\frac{P_{3}-P_{1}}{S_{i j, 3}-S_{i j, 1}}\right) \times\left(S_{i j}^{\text {limit }}-S_{i j, 1}\right)\right|, \\
P_{g, \Delta \delta}=P_{1}+\left|\left(\frac{P_{3}-P_{1}}{\Delta \delta_{g, 3}-\Delta \delta_{g, 1}}\right) \times\left(\Delta \delta^{\text {limit }}-\Delta \delta_{g, 1}\right)\right|,
\end{gathered}
$$

where $P_{i, V \text { lower }}, P_{i, V \text { upper }}, P_{i j, S}$ and $P_{g, \Delta \delta}$ are the linear estimation of power transfer based on the violations of lower voltage limit, upper voltage limit, thermal limit, and generator rotor angle difference limit, respectively. $V_{\text {lower }}$ and $V_{\text {upper }}$ are the lower and upper voltage limits which are 0.9 p.u. and 1.1 p.u., respectively. $S_{i j}^{\text {limit }}$ is the transmission line limit. $\Delta \delta^{\text {limit }}$ is the generator rotor angle difference limit which is $180^{\circ} . P_{n}$ is the power transfer for every $n$th incremental step. $n$ is incremental steps. $V_{i, n}, S_{i j, n}$ and $\Delta \delta_{g, n}$ are the voltage magnitude at each bus, $i$, power flow at each transmission line, $i j$, and maximum rotor angle difference at each generator bus, $g$, respectively.

The sensitive bus, $i$, transmission line, $i j$, or generator, $g$, is selected based on the minimum value of power transfer amongst $P_{i, V \text { lower }}, P_{i, V \text { upper }}, P_{i j, S}$, or $P_{g, \Delta \delta}$. $P_{\text {end }}$ represents as the minimum value of power transfer given by.

$$
P_{\text {end }}=\min \left\{P_{i, V \text { lower }}, P_{i, V \text { upper }}, P_{i j, S}, P_{g, \Delta \delta}\right\} \text {. }
$$

(d) Determine the look-ahead power transfer based on the sensitive bus, transmission line or generator. The methodology that is used to determine the look-ahead power transfer is initially derived from the formulation of second-order polynomial that is given in [22]. Further derivation of the first-order quadratic formulation in (2.6a) yields to,

$$
x=\frac{d y / d x-\beta}{2 \gamma} .
$$

Equation (3.7) is obtained by substituting (3.6) into (2.5),

$$
y=\alpha+\beta\left(\frac{d y / d x-\beta}{2 \gamma}\right)+\gamma\left(\frac{d y / d x-\beta}{2 \gamma}\right)^{2}
$$

By expanding (3.7),

$$
y=\alpha-\frac{\beta^{2}}{2 \gamma}+\frac{\beta(d y / d x)}{2 \gamma}+\frac{\beta^{2}}{4 \gamma}-\frac{\beta(d y / d x)}{2 \gamma}+\left(\frac{d y / d x}{2}\right)^{2}\left(\frac{1}{\gamma}\right)
$$

Equation (3.8) is derived to become

$$
y=y_{o}+\left(\frac{d y / d x}{2}\right)^{2}\left(\frac{1}{r}\right) .
$$


Whereby,

$$
y o=\alpha-\frac{\beta^{2}}{4 \gamma}
$$

By deriving (3.9),

$$
\frac{d y}{d x}=2 \sqrt{r(y-y o)}
$$

In this case, $y$ is the system parameter constraint such as the transmission line rating, lower limit of voltage magnitude that is 0.9 p.u., upper limit of voltage magnitude which is specified at 1.1 p.u., or generator rotor angle difference limit specified as $180^{\circ}$.

The look-ahead power transfer, $P_{\text {look }}$, is determined by using (3.12) which is derived from (2.6a). In (3.12), the $d y / d x$ is determined by using (3.11)

$$
P_{\text {look }}=x=\frac{|d y / d x-\beta|}{2 \gamma} \text {. }
$$

It is obvious that the look-ahead power transfer formulation in (3.12) is similar to (3.6). The $y_{o}$ and $d y / d x$ which are obtained by using (3.10) and (3.11), respectively, are used in (3.12) to determine the $P_{\text {look }}$. The values of $\alpha, \beta$ and $\gamma$ are calculated by using the least square method [12] that utilizes the $V_{n}, S_{n}$ or $\Delta \delta_{n}$ at three incremental steps of power transfer, $P_{n}$. The values of $V_{n}, S_{n}$ or $\Delta \delta_{n}$ are determined by referring to the sensitive bus, transmission line or generator obtained from procedure (c). This shows that the $P_{\text {look }}$ is determined by referring to the sensitive bus, transmission line or generator.

(e) Use the Ralston's method in (2.3) to determine the two trajectory points of voltage magnitude, power flow or maximum generator rotor angle difference. This refers to the sensitive bus, transmission line or generator obtained from procedure (c). Initially, the AC power flow solution is performed at three incremental steps of $P_{n}$ with $P_{3}=P_{\text {look}}$. This is performed to obtain the variation of $V_{n}, S_{n}$ or $\Delta \delta_{n}$ at the sensitive bus, transmission line or generator. Then, the $V_{n}, S_{n}$ or $\Delta \delta_{n}$, and $P_{n}$ are used in the least square method [12] to determine the new values of $\alpha, \beta$, and $\gamma$. The $P_{\text {look }}$ is specified as the last power transfer of $P_{n}$ so that $\alpha, \beta$, and $\gamma$ are determined at stable system condition. Hence, accurate estimation of two trajectory points could be obtained by using the Ralston's method that takes into account the $\alpha, \beta$ and $\gamma$. Specifically, the $\alpha, \beta, \gamma$ and $P_{\text {look }}$ are used in (2.6b), (2.6c), (2.6d) and (2.7a) so that the Ralston's method in (2.3) is able to determine the two trajectory points of voltage magnitude, power flow or maximum generator rotor angle difference. The $P_{\text {look }}$ is not an optimum value of ATC. Therefore, the Ralston's method is used to extrapolate at the two trajectory points for optimum or accurate determination of ATC.

(f) Use the cubic-spline to trace the $P-V, P-S$ or $P-\Delta \delta$ curve between the two points of trajectory. The $P-V, P-S$ or $P-\Delta \delta$ curve is determined based on the sensitive bus, transmission line or generator. 


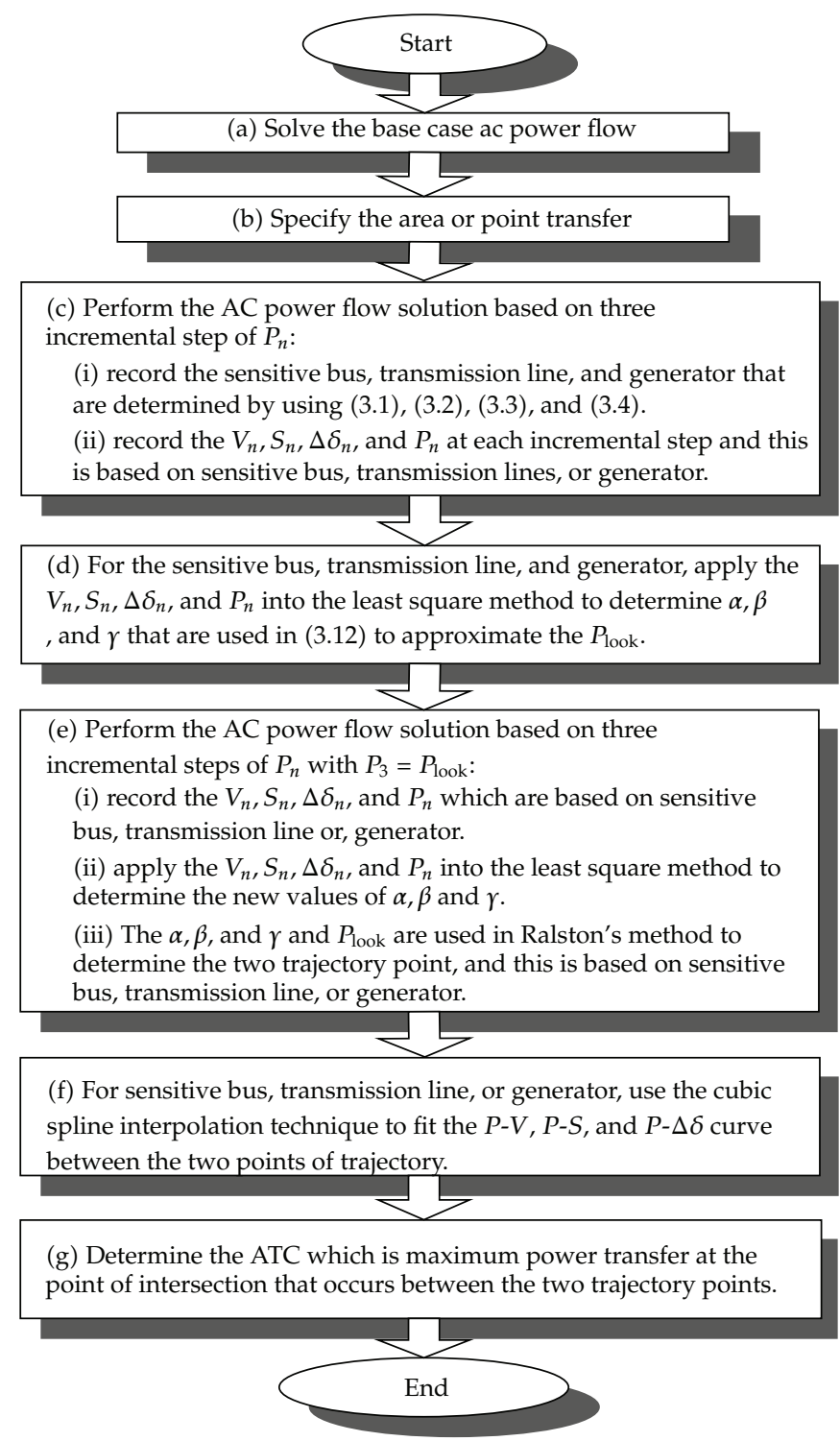

Figure 2: Outline of ATC computation using the Ralston's method incorporating cubic-spline interpolation technique.

(g) Determine area-to-area or point-to-point ATCs which are the maximum power transfer obtained when the voltage limit, the MVA line rating, or generator rotor angle difference limit intersects the $P-V, P-S$ or $P-\Delta \delta$ curve at two trajectory points, respectively.

The above procedures are summarized in terms of flowchart shown in Figure 2. The Ralston's method incorporating with cubic-spline interpolation technique gives a faster ATC computation which implies less AC power flow solutions as compared to the ATC computation method using the recursive AC Newton Raphson power flow solutions [4, 23]. 


\section{Results and Discussion}

The performance of the Ralston's method incorporating with cubic-spline interpolation technique that used in the determination of ATC is verified in terms of accuracy and computation speed. CPU timing for the transfer capability analysis was obtained using $2.4 \mathrm{GHz}$, Intel Core 2 Duo with $1 \mathrm{~GB}$ of memory. The 2737-bus Polish power system is used as a test case to illustrate the determination of ATC using the proposed technique. The system is comprising of 6 areas namely, area 1 , area 2, area 3, area 4, area 5, and area 6 . The 2737bus system is modelled with 193 generation units, 2544 load units and 3506 lines. In this study, the upper and lower voltage limits are assumed to be 1.1 p.u. and 0.9 p.u., respectively. The thermal limit is also used as a system constraint in the ATC computation. However, the generator rotor angle difference limit of $180^{\circ}$ is not considered in the ATC computation for the 2737-bus Polish power system. This is due to the fact that detailed information of generating unit is not available in order to compute ATC by considering the generator rotor angle difference limit.

Nevertheless, the generator rotor angle difference limit as well as the transmission line limit and voltage magnitude limit is considered as the constraints of ATC computation for a case study of 39-New England bus system. The system is consisting of 10 generation units, 29 load units and 46 transmission lines [24]. The system data is given in Tables 7, 8, and 9. The transmission line limit information is taken from [25]. The system is comprised into three areas namely area 1, area 2 and area 3 as illustrated in Figure 3.

\subsection{Faulted Bus and Tripping Line Selection}

The transient stability analysis is performed to ensure that the system is operating in a secure manner without violating the generator rotor angle limit during the occurrence of fault. In this case study of transfer capability assessment, it is assumed that a three-phase fault is occurring at a particular transmission line. The faulted bus is referring to as the nearest bus which is connected to a faulty line [17]. Therefore, the faulty line should be tripped in order to clear the fault so that a stable generator rotor angle could be obtained during power transfer.

\subsection{Fault Critical Clearing Time and Final Simulation Time Selection}

In a transient stability analysis, the faulty line should be tripped at a certain fault critical clearing time and this criterion does affect the stability of generator rotor angle. Therefore, a set of relays and protecting circuits should operate within the fault critical clearing time so that the fault is cleared without causing any loss of synchronism for the generators [26, 27]. However, the determination of fault critical clearing time is not considered in this case study of transfer capability assessment. Nevertheless, the fault critical clearing time is set at a typical maximum allowable time so that the generator rotor angle is stable during the occurrence of fault. In [28], an analysis to estimate the fault critical clearing time has been conducted on the 39-New England bus system. In conjunction to this system, the estimated fault critical clearing time for the 10 machines is best to be within the range of 0.13 to 0.24 second. Therefore, in this case study, the fault critical clearing time of 0.15 second is chosen to clear the fault. It is selected based on the fact that the fault is expected to be cleared before reaching the end of fault critical clearing time. Thus, the fault critical clearing time of 0.15 second is viable enough to ensure the stability of generator rotor angle. 


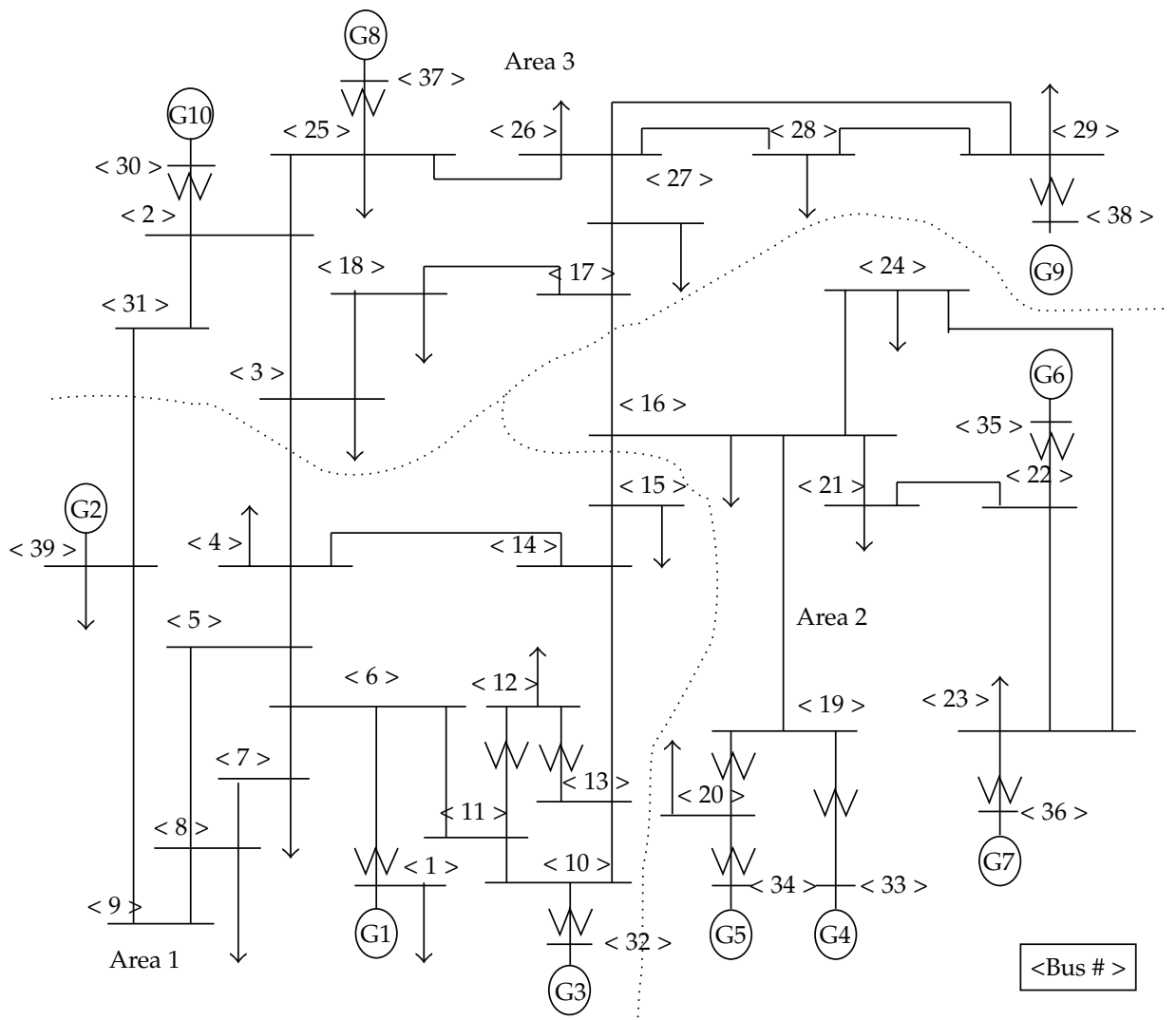

Figure 3: 39-New England Bus system.

The rotor angles with respect to the COI reference frame of all generators are initially increasing or decreasing until a peak value is reached. Then, the rotor angle starts returning to its stable equilibrium point and it is said to be the first swing stable. On the other hand, a system is said to be the first swing unstable if the postfault angle is increasing or decreasing monotonically for at least one of the machines [20, 28]. In this case study, duration for the simulation time is within the range of $t=0$ until $t_{f}=1.5$ seconds, and it is chosen as to analyze the stability of first swing generator rotor angle difference [20,28].

\subsection{ATC Results Using Ralston's Method Incorporating Cubic-Spline Interpolation Technique: Case Study of 2737-Bus Polish Power System}

Prior to the ATC determination, the cubic-spline interpolation technique is used to trace the $P-S$ or $P-V$ curves between the two points of trajectory determined by the Ralston's method. The ATC is then determined by referring to the maximum power transfer that causes the limiting levels of MVA power flow or voltage magnitude intersects the $P-S$ or $P-V$ curves, respectively. Detailed information of generating unit is not available for the computation of ATC computation considering the generator rotor angle difference limit. In this case study, the load bus 2737 is chosen to describe the determination of ATC using the proposed method. The load bus 2737 is a sensitive bus that limits the MW transfer from area 2 to area 6 . 


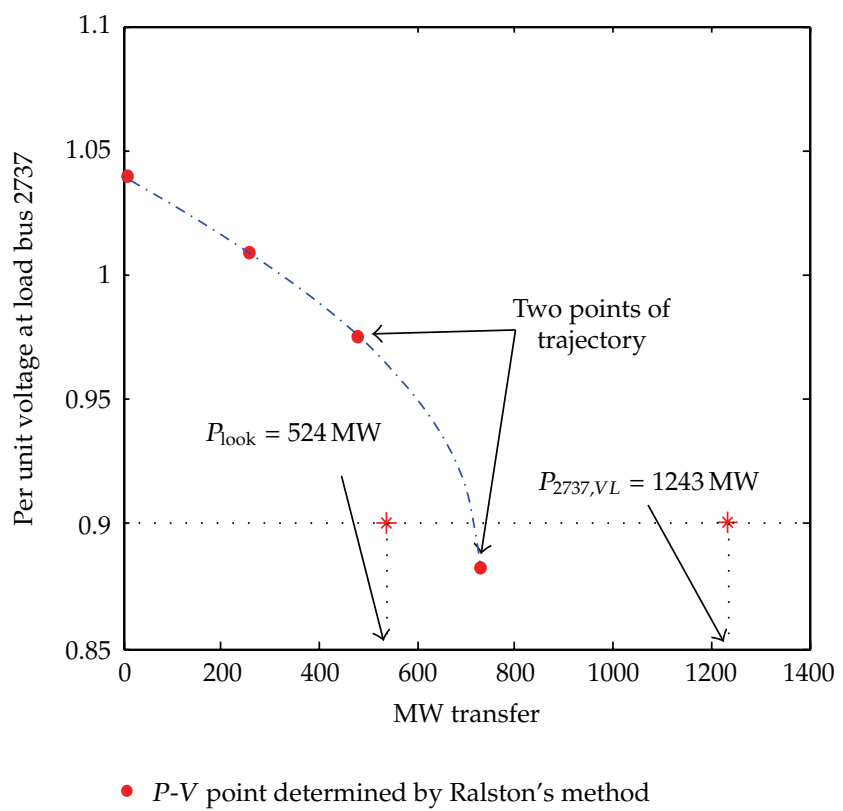

Figure 4: Two points of trajectory at bus 2737 using the Ralston's method.

By referring to Figure 4, the sensitivity method given in (3.1) linearly determines the amount of ATC, $P_{2737, V l o w e r}=1243 \mathrm{MW}$, that violates the lower limit of voltage magnitude. Linear approximation of power transfer considered in the sensitivity method usually gives inaccurate value of ATC especially for a large system. In the AC power flow solution, the amount of $P_{2737, V l o w e r}=1243 \mathrm{MW}$ could be very large, which may cause instability to the system condition. Hence, accurate nonlinear estimation of ATC could be obtained by considering the quadratic form of $P-V$ or $P-S$ curves. In this case study, the sensitivity method is used to determine the sensitive bus or transmission line which is based on the minimum amount of power transfer as given in (3.5). The sensitive bus or transmission line has the potential to cause the first violation of voltage magnitude or thermal limits due to the increase of power transfer, respectively. Hence, fast and accurate estimation of ATC could be determined by referring only to the sensitive bus or transmission line. In this case study, the sensitive load bus 2737 limits the power transfer between area 2 to area 6 , and it is shown in Figure 4. In Figure 4, it is observed that the $P_{\text {look }}=524 \mathrm{MW}$ does not exceed the power transfer at the second trajectory point of voltage magnitude. Hence, the system condition is stable when $P_{\text {look }}=524 \mathrm{MW}$ is below the second trajectory point. The $P_{\text {look }}$ is not an optimum or accurate value of ATC, and it is determined by using (3.12). However, the unstable system conditions may occur when power transfer exceeds the second trajectory point. Therefore, the $P_{\text {look }}$ value of $524 \mathrm{MW}$ is used in the Ralston's method to accurately extrapolate at the two trajectory points for optimum or accurate estimation of ATC. Figure 4 shows four incremental steps $(n)$ performed of power transfer by using the Ralston's method.

The cubic-spline interpolation technique is then used to fit the $P-V$ curve between the two trajectory points at the sensitive bus 2737 . The two trajectory points are at the power transfer of $462 \mathrm{MW}$ and $720 \mathrm{MW}$. The power transfer at the two trajectory points is then used in the cubic-spline interpolation technique for $P-V$ curve fitting. In Figure 5, it is shown that the cubic-spline interpolation technique traces the $P-V$ curve based on the four points of 


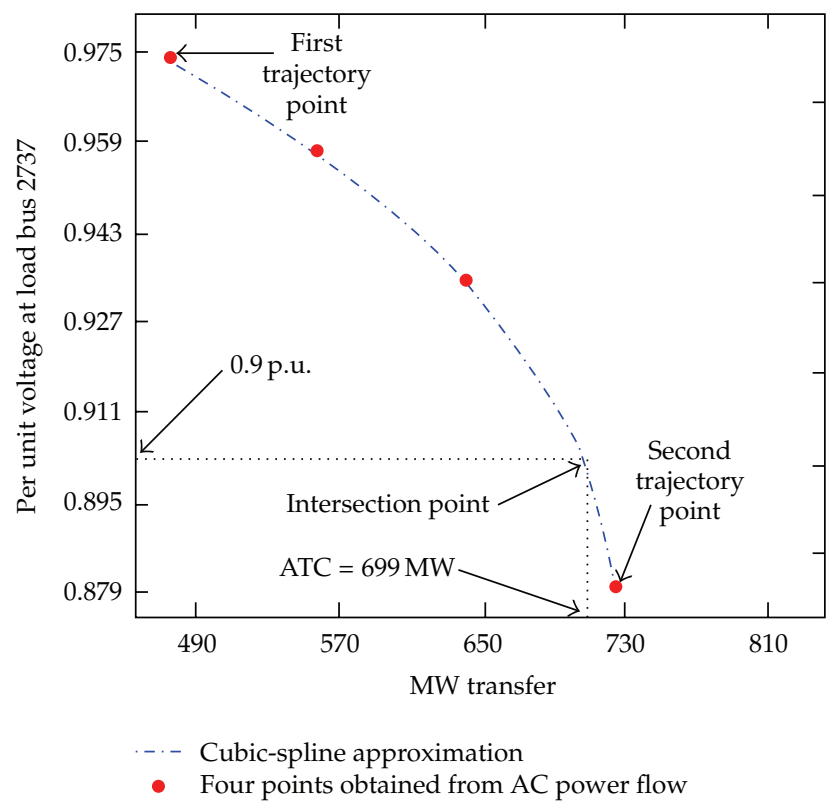

Figure 5: $P-V$ curve traced at bus 2737 using the cubic-spline interpolation technique.

voltage magnitude. The four points of voltage magnitude are obtained from the AC power flow solutions considering the power transfers of $462 \mathrm{MW}, 548 \mathrm{MW}, 634 \mathrm{MW}$ and $720 \mathrm{MW}$. A point is noted where voltage limit of $0.9 \mathrm{p} . \mathrm{u}$. intersects the $P-V$ curve. This point yields an actual ATC value of $699 \mathrm{MW}$.

\subsection{Results of Area-To-Area ATC and Point-To-Point ATC: Case Study of 2737-Bus Polish Power System}

Tables 1 and 2 represent the results of the area-to-area ATC and the point-to-point ATC, respectively. The ATCs obtained from the Ralston's method incorporating with cubic-spline interpolation technique are compared with the ATCs obtained from the recursive AC power flow method. The comparisons are made in terms of accuracy and time taken in computing the ATC.

The results shown in Tables 1 and 2 indicate that the ATC obtained is due to the overloaded line. For instance, by referring to Table 1, the ATC is $914 \mathrm{MW}$ for transfer case between areas 1 and 2, and it is obtained due to the overloaded line 713-449. The overloaded line that limits the increase of power transfer occurs for the transfer case between buses. For an example, by referring to Table 2, the ATC is $140 \mathrm{MW}$ for the transfer case between buses 98 and 2636, and it is obtained due to the overloaded line 2507-2513. Simulations that have been carried out on the test system indicate that the ATCs are determined not due to the violation of voltage limit.

The recursive AC power flow method is a basic approach to determine accurate value of ATC. This means that the proposed method is able to compute accurate value of ATC since it is similar to the result determined by the recursive AC power flow method, and it is shown in Tables 1 and 2. Both methods are able to calculate accurate value of ATC since they 
Table 1: Results of area-to-area ATC for the 2737-bus polish power system.

\begin{tabular}{|c|c|c|c|c|c|c|c|c|}
\hline \multicolumn{2}{|c|}{ Area of transfers } & \multirow{2}{*}{$\begin{array}{l}\text { Limiting } \\
\text { line }\end{array}$} & \multicolumn{2}{|c|}{ ATC (MW) } & \multicolumn{2}{|c|}{ CPU time (minute) } & \multicolumn{2}{|c|}{$\begin{array}{l}\text { Number of load flow } \\
\text { solutions }\end{array}$} \\
\hline $\begin{array}{l}\text { Selling } \\
\text { area }\end{array}$ & $\begin{array}{c}\text { Buying } \\
\text { area }\end{array}$ & & $\begin{array}{l}\text { Ralston's } \\
\text { with } \\
\text { cubic- } \\
\text { spline }\end{array}$ & $\begin{array}{l}\text { Recursive } \\
\text { AC power } \\
\text { flow }\end{array}$ & $\begin{array}{l}\text { Ralston's } \\
\text { with } \\
\text { cubic- } \\
\text { spline }\end{array}$ & $\begin{array}{c}\text { Recursive } \\
\text { AC power } \\
\text { flow }\end{array}$ & $\begin{array}{l}\text { Ralston's } \\
\text { with } \\
\text { cubic- } \\
\text { spline }\end{array}$ & $\begin{array}{c}\text { Recursive } \\
\text { AC power } \\
\text { flow }\end{array}$ \\
\hline 1 & 2 & $713-449$ & 914 & 914 & 0.31 & 38.68 & 10 & 914 \\
\hline 1 & 3 & $91-131$ & 953 & 953 & 0.32 & 40.19 & 10 & 953 \\
\hline 1 & 4 & 2092-1972 & 655 & 655 & 0.33 & 41.17 & 10 & 655 \\
\hline 1 & 5 & 2562-2092 & 182 & 183 & 0.31 & 38.68 & 10 & 183 \\
\hline 1 & 6 & 2737-1872 & 175 & 175 & 0.29 & 36.18 & 10 & 175 \\
\hline 2 & 1 & 2562-2092 & 1472 & 1472 & 0.32 & 40.31 & 10 & 1472 \\
\hline 2 & 3 & $1593-741$ & 1088 & 1087 & 0.33 & 41.87 & 10 & 1087 \\
\hline 2 & 4 & 2092-1972 & 655 & 655 & 0.32 & 40.22 & 10 & 655 \\
\hline 2 & 5 & 2562-2092 & 194 & 193 & 0.29 & 37.04 & 10 & 193 \\
\hline 2 & 6 & 2737-1872 & 175 & 175 & 0.31 & 38.65 & 10 & 175 \\
\hline 3 & 1 & 2562-2092 & 593 & 593 & 0.31 & 38.67 & 10 & 593 \\
\hline 3 & 2 & 2562-2092 & 982 & 981 & 0.30 & 38.34 & 10 & 981 \\
\hline 3 & 4 & 2092-1972 & 727 & 726 & 0.33 & 41.32 & 10 & 726 \\
\hline 3 & 5 & 2562-2092 & 160 & 161 & 0.31 & 38.66 & 10 & 161 \\
\hline 3 & 6 & 2737-1872 & 175 & 175 & 0.30 & 37.01 & 10 & 175 \\
\hline 4 & 1 & $2216-2092$ & 14 & 14 & 0.29 & 37.06 & 10 & 14 \\
\hline 4 & 2 & $2216-2092$ & 14 & 14 & 0.32 & 40.56 & 10 & 14 \\
\hline 4 & 3 & $2216-2092$ & 14 & 14 & 0.35 & 44.53 & 10 & 14 \\
\hline 4 & 5 & $2216-2092$ & 21 & 20 & 0.30 & 37.12 & 10 & 20 \\
\hline 4 & 6 & 2216-2092 & 14 & 14 & 0.31 & 37.41 & 10 & 14 \\
\hline 5 & 1 & $2216-2092$ & 35 & 34 & 0.32 & 40.13 & 10 & 34 \\
\hline 5 & 2 & $2216-2092$ & 34 & 34 & 0.32 & 40.75 & 10 & 34 \\
\hline 5 & 3 & $2216-2092$ & 34 & 34 & 0.33 & 41.75 & 10 & 34 \\
\hline 5 & 4 & $2216-2092$ & 174 & 173 & 0.34 & 42.47 & 10 & 173 \\
\hline 5 & 6 & $2216-2092$ & 34 & 34 & 0.31 & 36.11 & 10 & 34 \\
\hline 6 & 1 & 2216-2092 & 128 & 128 & 0.33 & 40.73 & 10 & 128 \\
\hline 6 & 2 & $2216-2092$ & 125 & 125 & 0.32 & 39.91 & 10 & 125 \\
\hline 6 & 3 & $2216-2092$ & 121 & 121 & 0.34 & 41.18 & 10 & 121 \\
\hline 6 & 4 & $696-453$ & 929 & 929 & 0.33 & 41.14 & 10 & 929 \\
\hline 6 & 5 & 2562-2092 & 133 & 132 & 0.31 & 38.12 & 10 & 132 \\
\hline
\end{tabular}

considers nonlinear condition of reactive power flows and voltage magnitudes. The proposed method is better than the linear DC power flow method in terms of accuracy for the ATC computation. In terms of computational time, it is noted that the proposed method computes a much faster ATC value as compared to the recursive AC power flow method. This is due to the fact that the proposed method does not perform many recursive load flow solutions in the ATC determination. Finally, the results have shown that the proposed method is able to provide accurate value of ATC with less computational time. 
Table 2: Results of point-to-point ATC for the 2737-bus polish power system.

\begin{tabular}{|c|c|c|c|c|c|c|c|c|}
\hline \multicolumn{2}{|c|}{ Point of transfers } & \multirow[t]{2}{*}{$\begin{array}{l}\text { Limiting } \\
\text { line }\end{array}$} & \multicolumn{2}{|c|}{ ATC (MW) } & \multicolumn{2}{|c|}{ CPU time (minute) } & \multicolumn{2}{|c|}{$\begin{array}{l}\text { Number of load flow } \\
\text { solutions }\end{array}$} \\
\hline $\begin{array}{l}\text { Selling } \\
\text { bus }\end{array}$ & $\begin{array}{l}\text { Buying } \\
\text { bus }\end{array}$ & & $\begin{array}{c}\text { Ralston's } \\
\text { with } \\
\text { cubic- } \\
\text { spline }\end{array}$ & $\begin{array}{c}\text { Recursive } \\
\text { AC power } \\
\text { flow }\end{array}$ & $\begin{array}{c}\text { Ralston's } \\
\text { with } \\
\text { cubic- } \\
\text { spline }\end{array}$ & $\begin{array}{c}\text { Recursive } \\
\text { AC power } \\
\text { flow }\end{array}$ & $\begin{array}{c}\text { Ralston's } \\
\text { with } \\
\text { cubic- } \\
\text { spline }\end{array}$ & $\begin{array}{l}\text { Recursive } \\
\text { AC power } \\
\text { flow }\end{array}$ \\
\hline 98 & 2636 & 2507-2513 & 140 & 140 & 0.29 & 15.33 & 10 & 140 \\
\hline 2555 & 108 & $108-90$ & 419 & 419 & 0.28 & 15.01 & 10 & 419 \\
\hline 2727 & 1038 & 1260-1839 & 110 & 110 & 0.30 & 15.89 & 10 & 110 \\
\hline 323 & 1000 & 1001-1441 & 177 & 176 & 0.29 & 15.17 & 10 & 176 \\
\hline 26 & 205 & 2562-2092 & 376 & 376 & 0.29 & 15.60 & 10 & 376 \\
\hline 1025 & 1564 & 1566-1564 & 83 & 82 & 0.29 & 15.17 & 10 & 82 \\
\hline 55 & 86 & 91-131 & 589 & 589 & 0.28 & 14.89 & 10 & 589 \\
\hline 1992 & 2004 & 2250-1984 & 157 & 156 & 0.28 & 14.90 & 10 & 156 \\
\hline 117 & 1 & $26-1$ & 642 & 641 & 0.29 & 15.55 & 10 & 641 \\
\hline 240 & 125 & 514-319 & 345 & 345 & 0.28 & 14.99 & 10 & 345 \\
\hline 158 & 978 & 1212-1014 & 247 & 246 & 0.28 & 14.98 & 10 & 246 \\
\hline 977 & 833 & 977-1278 & 128 & 128 & 0.29 & 15.16 & 10 & 128 \\
\hline 878 & 620 & $719-620$ & 90 & 90 & 0.28 & 15.09 & 10 & 90 \\
\hline 793 & 300 & $793-592$ & 148 & 148 & 0.28 & 15.06 & 10 & 148 \\
\hline 665 & 430 & $392-351$ & 108 & 107 & 0.29 & 15.31 & 10 & 107 \\
\hline 574 & 99 & $1929-420$ & 254 & 253 & 0.29 & 15.18 & 10 & 253 \\
\hline 444 & 65 & $444-432$ & 120 & 120 & 0.28 & 15.09 & 10 & 120 \\
\hline 764 & 752 & $752-681$ & 104 & 103 & 0.29 & 15.32 & 10 & 103 \\
\hline 2731 & 2 & $696-453$ & 161 & 161 & 0.29 & 15.36 & 10 & 161 \\
\hline 135 & 2737 & 2737-1872 & 74 & 73 & 0.29 & 15.48 & 10 & 73 \\
\hline 1006 & 1921 & 1921- 856 & 90 & 90 & 0.28 & 15.01 & 10 & 90 \\
\hline 1673 & 1781 & $1781-1234$ & 246 & 246 & 0.28 & 14.88 & 10 & 246 \\
\hline 366 & 628 & $632-628$ & 73 & 72 & 0.29 & 15.23 & 10 & 72 \\
\hline 56 & 533 & $528-355$ & 155 & 155 & 0.28 & 15.03 & 10 & 155 \\
\hline 135 & 378 & $250-248$ & 86 & 85 & 0.27 & 15.16 & 10 & 85 \\
\hline 150 & 164 & 2216-2092 & 98 & 97 & 0.28 & 15.13 & 10 & 97 \\
\hline 221 & 165 & 2065-221 & 55 & 55 & 0.26 & 14.10 & 10 & 55 \\
\hline 222 & 212 & $530-523$ & 74 & 73 & 0.29 & 15.22 & 10 & 73 \\
\hline 2097 & 1019 & 2097-2252 & 104 & 104 & 0.30 & 15.24 & 10 & 104 \\
\hline 2279 & 1227 & 2216-2092 & 50 & 50 & 0.25 & 14.39 & 10 & 50 \\
\hline
\end{tabular}

\subsection{Results of Area-To-Area ATC and Point-To-Point ATC: Case Study of 39-New England Bus System}

Tables 3 and 4 present the result of area-to-area ATCs and point-to-point ATCs for a test system of 39-New England buses, respectively. The ATCs are determined by considering the systems constraints of transmission line limit, voltage stability limit, and generator rotor angle difference limit. Whereby, the rotor angle difference limit is referred to as the transient 
Table 3: Results of area-to-area ATC for the 39-New England bus system.

\begin{tabular}{|c|c|c|c|c|c|c|c|c|}
\hline \multicolumn{2}{|c|}{ Area of transfers } & \multirow{2}{*}{$\begin{array}{l}\text { Limiting } \\
\text { line }\end{array}$} & \multicolumn{2}{|c|}{ ATC (MW) } & \multicolumn{2}{|c|}{ CPU time (minute) } & \multicolumn{2}{|c|}{$\begin{array}{l}\text { Number of load flow } \\
\text { solutions }\end{array}$} \\
\hline $\begin{array}{l}\text { Selling } \\
\text { area }\end{array}$ & $\begin{array}{l}\text { Buying } \\
\text { area }\end{array}$ & & $\begin{array}{c}\text { Ralston's } \\
\text { with } \\
\text { cubic- } \\
\text { spline }\end{array}$ & $\begin{array}{c}\text { Recursive } \\
\text { AC power } \\
\text { flow }\end{array}$ & $\begin{array}{l}\text { Ralston's } \\
\text { with } \\
\text { cubic- } \\
\text { spline }\end{array}$ & $\begin{array}{l}\text { Recursive } \\
\text { AC power } \\
\text { flow }\end{array}$ & $\begin{array}{c}\text { Ralston's } \\
\text { with } \\
\text { cubic- } \\
\text { spline }\end{array}$ & $\begin{array}{l}\text { Recursive } \\
\text { AC power } \\
\text { flow }\end{array}$ \\
\hline 1 & 2 & $12-13$ & 64 & 64 & 0.03 & 0.17 & 18 & 64 \\
\hline 1 & 3 & $12-13$ & 79 & 78 & 0.03 & 0.20 & 18 & 78 \\
\hline 2 & 1 & $14-15$ & 182 & 182 & 0.03 & 0.45 & 18 & 182 \\
\hline 2 & 3 & $14-15$ & 350 & 349 & 0.03 & 0.84 & 18 & 349 \\
\hline 3 & 1 & 3-4 & 323 & 323 & 0.03 & 0.80 & 18 & 323 \\
\hline 3 & 2 & $12-13$ & 277 & 277 & 0.03 & 0.67 & 18 & 277 \\
\hline
\end{tabular}

stability limit. In this case study, it is assumed that a single (N-1) contingency type of threephase fault happened at bus 10. A three-phase fault yields the most severe fault current compared to the other types of unsymmetrical fault. The computation of ATCs due to transient stability limit is performed by considering the tripping of line 10-13 for clearing the fault. The fault critical clearing time of $t=0.15$ second, is specified for the tripping at line 10-13. The selection of fault critical clearing time, $t=0.15$ second has been explained elaborately in Section 4.2. The transient response of generator rotor angles is monitored for 1.5 seconds in the case study of ATC that takes into account the transient stability limit. Since, the tripping of line 10-13 is taken into account in the determination of ATC considering the transient stability limit the tripping of line $10-13$ is considered as a single $(\mathrm{N}-1)$ contingency of three phase fault. On the other side, a double (N-2) contingency may sometimes occur, which would be critical to the system operating conditions especially during the power transfer. Indeed, this is an intriguing issue that needs be considered for further analysis on the impact of $\mathrm{N}-2$ contingencies on the transfer capability assessment-based transient stability limit. In the transient stability analysis, a small time step size of 0.03 second is used in the time-domain of rotor angle. The small time step size is used to discard the higher-order terms of Taylor series expansion used in the Euler's method. Therefore, the error of rotor angle approximation is decreased for every successive point of time domain [17].

In Table 3, the minimum interarea ATC of $64 \mathrm{MW}$ is obtained for the transfer case from area 1 to area 2 and the transfer case from area 2 to area 3 yields a maximum interarea ATC value of $350 \mathrm{MW}$. On the other hand, by referring to Table 4, the minimum point-to-point ATC of $41 \mathrm{MW}$ is obtained for the power transfer from bus 32 to bus 24 . The power transfer case from bus 34 to bus 26 yields a maximum point-to-point ATC value of $353 \mathrm{MW}$. For both cases of power transfer, the ATCs are obtained based on the violation of transmission line limit. It is obvious that the proposed method provides relatively similar results of ATC compared to the recursive AC power flow method. In terms of computational time, it is obvious that the proposed technique gives a fast ATC calculation compared to the recursive AC power flow method. This is because the Ralston's method incorporated with the cubic-spline interpolation technique executes fewer numbers of power flow solution in the ATC determination in comparison to the recursive AC power flow method. 
Table 4: Results of point-to-point ATC for the 39-New England bus system.

\begin{tabular}{|c|c|c|c|c|c|c|c|c|}
\hline & \multirow{2}{*}{$\begin{array}{l}\text { Limiting } \\
\text { line }\end{array}$} & \multicolumn{2}{|c|}{ ATC (MW) } & \multicolumn{2}{|c|}{ CPU Time (minute) } & \multicolumn{2}{|c|}{$\begin{array}{l}\text { Number of load flow } \\
\text { solutions }\end{array}$} \\
\hline $\begin{array}{l}\text { Selling } \\
\text { bus }\end{array}$ & $\begin{array}{c}\text { Buying } \\
\text { bus }\end{array}$ & & $\begin{array}{c}\text { Ralston's } \\
\text { with } \\
\text { cubic- } \\
\text { spline }\end{array}$ & $\begin{array}{l}\text { Recursive } \\
\text { AC power } \\
\text { flow }\end{array}$ & $\begin{array}{c}\text { Ralston's } \\
\text { with } \\
\text { cubic- } \\
\text { spline }\end{array}$ & $\begin{array}{c}\text { Recursive } \\
\text { AC power } \\
\text { flow }\end{array}$ & $\begin{array}{l}\text { Ralston's } \\
\text { with } \\
\text { cubic- } \\
\text { spline }\end{array}$ & $\begin{array}{l}\text { Recursive } \\
\text { AC power } \\
\text { flow }\end{array}$ \\
\hline 30 & 16 & $2-30$ & 236 & 235 & 0.03 & 0.60 & 18 & 235 \\
\hline 30 & 20 & $19-20$ & 128 & 127 & 0.03 & 0.32 & 18 & 127 \\
\hline 30 & 3 & $2-30$ & 233 & 233 & 0.03 & 0.58 & 18 & 233 \\
\hline 32 & 3 & $12-13$ & 48 & 47 & 0.03 & 0.12 & 18 & 47 \\
\hline 32 & 24 & $12-13$ & 41 & 40 & 0.03 & 0.10 & 18 & 40 \\
\hline 32 & 27 & $12-13$ & 44 & 44 & 0.03 & 0.11 & 18 & 44 \\
\hline 33 & 3 & 3-18 & 128 & 128 & 0.03 & 0.32 & 18 & 128 \\
\hline 33 & 24 & $16-24$ & 291 & 291 & 0.03 & 0.73 & 18 & 291 \\
\hline 33 & 27 & $17-27$ & 293 & 292 & 0.03 & 0.74 & 18 & 292 \\
\hline 34 & 4 & $14-15$ & 131 & 130 & 0.03 & 0.33 & 18 & 130 \\
\hline 34 & 25 & 3-18 & 196 & 195 & 0.03 & 0.48 & 18 & 195 \\
\hline 34 & 26 & $17-27$ & 353 & 352 & 0.03 & 0.85 & 18 & 352 \\
\hline 35 & 3 & 3-18 & 127 & 127 & 0.03 & 0.32 & 18 & 127 \\
\hline 35 & 15 & $15-16$ & 145 & 145 & 0.03 & 0.36 & 18 & 145 \\
\hline 35 & 27 & $16-21$ & 268 & 267 & 0.03 & 0.65 & 18 & 267 \\
\hline 36 & 12 & $14-15$ & 117 & 117 & 0.03 & 0.29 & 18 & 117 \\
\hline 36 & 28 & $16-21$ & 329 & 329 & 0.03 & 0.80 & 18 & 329 \\
\hline 36 & 3 & 3-18 & 127 & 127 & 0.03 & 0.31 & 18 & 127 \\
\hline 37 & 15 & $12-13$ & 186 & 186 & 0.03 & 0.46 & 18 & 186 \\
\hline 37 & 24 & $12-13$ & 241 & 241 & 0.03 & 0.60 & 18 & 241 \\
\hline 37 & 26 & $25-26$ & 243 & 243 & 0.03 & 0.60 & 18 & 243 \\
\hline 38 & 3 & 3-18 & 174 & 173 & 0.03 & 0.43 & 18 & 173 \\
\hline 38 & 8 & 29-38 & 176 & 176 & 0.03 & 0.44 & 18 & 176 \\
\hline 38 & 24 & 29-38 & 176 & 176 & 0.03 & 0.44 & 18 & 176 \\
\hline 39 & 21 & $12-13$ & 103 & 102 & 0.03 & 0.26 & 18 & 102 \\
\hline 39 & 22 & $12-13$ & 102 & 102 & 0.03 & 0.27 & 18 & 102 \\
\hline 39 & 24 & $12-13$ & 103 & 102 & 0.03 & 0.35 & 18 & 102 \\
\hline
\end{tabular}

\subsection{Performance Comparison of Ralston's Method Incorporating with Cubic-Spline Interpolation Technique at Various Numbers of Steps in Power Transfer: Case Study of 39-New England Bus System}

Table 5 presents the performance of area-to-area ATC computation based on several numbers of steps, $n$, applied in the proposed method. The same case study as discussed in Section 4.5 is used in this analysis. Basically, the power transfer step size, $h$, is specified depending on the number of steps, $n$, applied in (2.6d). The performance of the proposed technique is evaluated based on four difference numbers of steps, $n$. In addition, the percentage of relative error in applying the proposed method to determine the ATC is also computed for every transaction in the case study. By comparing the ATC values obtained in Tables 3 and 5, the interarea 
Table 5: Performance of Ralston's method incorporating with cubic-spline interpolation technique.

\begin{tabular}{|c|c|c|c|c|c|c|c|c|c|c|c|c|c|c|}
\hline & & & ATC & (MW & & & & & & & & & & \\
\hline Area of & transfers & $\begin{array}{l}\text { Recursive } \\
\text { AC }\end{array}$ & $\begin{array}{l}\text { Ralst } \\
\text { cubic }\end{array}$ & $\begin{array}{l}\text { on's w } \\
\text { spline }\end{array}$ & & & $\begin{array}{l}\text { Relati } \\
\text { perce }\end{array}$ & $\begin{array}{l}\text { ive err } \\
\text { ntage }\end{array}$ & $\begin{array}{l}\text { ror } \\
(\%)\end{array}$ & & $\mathrm{CP}$ & U time & e $(\min 1$ & utes) \\
\hline & & Power & & Imber & of ste & ps, $n$ & & umber & of ster & $\mathrm{ps}, n$ & & umber & of step & os, $n$ \\
\hline $\begin{array}{l}\text { Selling } \\
\text { area }\end{array}$ & $\begin{array}{c}\text { Buying } \\
\text { area }\end{array}$ & Flow & $n=3$ & $n=$ & $n=6$ & $n=20$ & $n=3$ & $n=$ & $n=$ & $n=20$ & $n=3$ & $n=4$ & $n=6$ & $n=20$ \\
\hline 1 & 2 & 64 & 66 & 64 & 64 & 64 & 3.13 & 0.0 & 0.0 & 0.0 & 0.03 & 0.03 & 0.03 & 0.05 \\
\hline 1 & 3 & 78 & 81 & 79 & 79 & 78 & 3.85 & 1.28 & 1.28 & 0.0 & 0.03 & 0.03 & 0.03 & 0.05 \\
\hline 2 & 1 & 182 & 184 & 182 & 182 & 182 & 1.09 & 0.0 & 0.0 & 0.0 & 0.03 & 0.03 & 0.03 & 0.05 \\
\hline 2 & 3 & 349 & 352 & 350 & 350 & 349 & 0.57 & 0.29 & 0.29 & 0.0 & 0.03 & 0.03 & 0.03 & 0.05 \\
\hline 3 & 1 & 323 & 325 & 323 & 323 & 323 & 0.62 & 0.0 & 0.0 & 0.0 & 0.03 & 0.03 & 0.03 & 0.05 \\
\hline 3 & 2 & 277 & 278 & 277 & 277 & 277 & 0.36 & 0.0 & 0.0 & 0.0 & 0.03 & 0.03 & 0.03 & 0.05 \\
\hline
\end{tabular}

Table 6: Results of area-to-area ATC due to transient stability limit.

\begin{tabular}{|c|c|c|c|c|c|c|c|c|c|}
\hline \multicolumn{2}{|c|}{ Area of transfers } & \multicolumn{2}{|c|}{ Limiting generator } & \multicolumn{2}{|c|}{ ATC (MW) } & \multicolumn{2}{|c|}{ CPU time (minute) } & \multicolumn{2}{|c|}{$\begin{array}{l}\text { Number of load flow } \\
\text { solutions }\end{array}$} \\
\hline $\begin{array}{l}\text { Selling } \\
\text { area }\end{array}$ & $\begin{array}{l}\text { Buying } \\
\text { area }\end{array}$ & Bus & $\begin{array}{l}\text { Generator } \\
\text { unit }\end{array}$ & $\begin{array}{l}\text { Ralston's } \\
\text { with } \\
\text { cubic- } \\
\text { spline }\end{array}$ & $\begin{array}{c}\text { Recursive } \\
\text { AC power } \\
\text { flow }\end{array}$ & $\begin{array}{c}\text { Ralston's } \\
\text { with } \\
\text { cubic- } \\
\text { spline }\end{array}$ & $\begin{array}{c}\text { Recursive } \\
\text { AC power } \\
\text { flow }\end{array}$ & $\begin{array}{l}\text { Ralston's } \\
\text { with } \\
\text { cubic- } \\
\text { spline }\end{array}$ & $\begin{array}{c}\text { Recursive } \\
\text { AC power } \\
\text { flow }\end{array}$ \\
\hline 1 & 2 & 32 & G3 & 448 & 449 & 0.03 & 1.37 & 18 & 449 \\
\hline 1 & 3 & 32 & G3 & 449 & 449 & 0.03 & 1.20 & 18 & 449 \\
\hline 2 & 1 & 34 & G5 & 858 & 857 & 0.03 & 1.81 & 18 & 857 \\
\hline 2 & 3 & 34 & G5 & 870 & 870 & 0.03 & 2.20 & 18 & 870 \\
\hline 3 & 1 & 38 & G9 & 660 & 660 & 0.08 & 1.62 & 18 & 660 \\
\hline 3 & 2 & 38 & G9 & 723 & 722 & 0.03 & 1.90 & 18 & 722 \\
\hline
\end{tabular}

transactions computed by using the proposed technique with $n=3$ gives the range of relative error percentage within $0.36 \%$ to $3.85 \%$. Most of these transactions are $2 \mathrm{MW}$ higher than the ATC values obtained by using the recursive AC power flow solution. This is referring to the case study of interarea power transfer from selling area 1 to buying area 2, selling area 2 to buying area 1, and selling area 3 to buying area 1 . The highest percentage of relative error of $3.85 \%$ is obtained from selling area 1 to buying area 3 . Furthermore, the performance of the proposed method in ATC computation is evaluated based on $n=4$ and $n=6$ incremental steps of power transfer. It is observed that the proposed method with $n=4$ and $n=6$ gives relatively similar results as compared to the ATCs obtained by using the recursive AC power flow solution as shown in Table 3. This indicates that it is important to use $n=4$ and $n=6$ in the Ralston's method for accurate extrapolation at the two trajectory points. Therefore, it will give relatively accurate value of ATC compared to the result determined by the Ralston's method with $n=3$. Besides that, the Ralston's method with the number of steps specified at $n=4$ and $n=6$ also gives less percentage of relative error at $1.28 \%$ and $0.29 \%$ from the selling area 1 to buying area 3 and selling area 2 to buying area 3, respectively. In Table 5, it is observed that the proposed method with $n=20$ gives similar results compared to the ATCs obtained by using the recursive AC power flow solution as shown in Table 3 . This is due to the fact that as the number of steps, $n$, is increased, the power transfer step size, $h$, will become 
Table 7: 39-New England machine data.

\begin{tabular}{lcccc}
\hline Unit No. & Bus No. & Ra & X'd & H (seconds) \\
\hline G1 & 1 & 0 & 0.0697 & 30.3 \\
G2 & 39 & 0 & 0.0697 & 500.0 \\
G3 & 32 & 0 & 0.0060 & 35.8 \\
G4 & 33 & 0 & 0.0531 & 28.6 \\
G5 & 34 & 0 & 0.0436 & 26.0 \\
G6 & 35 & 0 & 0.1320 & 34.8 \\
G7 & 36 & 0 & 0.0500 & 26.4 \\
G8 & 37 & 0 & 0.0490 & 24.3 \\
G9 & 38 & 0 & 0.0570 & 34.5 \\
G10 & 30 & 0 & 0.0310 & 42.0 \\
\hline
\end{tabular}

narrow. This may assist towards a better result of curve fitting performed by the cubic-spline interpolation technique. Thus, accurate estimation of ATC result can be obtained.

In terms of computational time, the Ralston's method with, $n=3, n=4$ and $n=6$ is utilizing the same computational time of 1.8 seconds in determining the ATC. However, it is much faster than the Ralston's method with $n=20$ that takes 0.05 minutes in determining the value of ATC. It is obvious that $n=4$ and $n=6$ improves the performance of Ralston's method which gives similar results of ATC with less computational time. By referring to the above-mentioned detail explanations, the proposed method with $n=4$ is used in the other power transfer case study for a fast and accurate estimation of ATC.

\subsection{Determination of ATC due to the Transient Stability Limit}

This section discusses the variations of maximum generator rotor angle difference that is used in (3.4) to determine the sensitive generator. The sensitivity method given in (3.4) is used to identify the generator that has the highest potential to be violated due to the increased amount of power transfer [21]. The sensitive generator is important for the proposed method that assists towards fast computation of ATC. This is because the increase of power transfer that varies the maximum amount of generator rotor angle difference is observed only at the sensitive generator.

In order to observe the variations of maximum generator rotor angle differences, therefore, the power transfer is increased at 3 stages, which are $1 \mathrm{MW}, 150.5 \mathrm{MW}$, and $300 \mathrm{MW}$ for the transfer case from area 2 to area 3 and it is shown in Figure 6. It is observed that generator G5 gives rapid changes of maximum generator rotor angle difference due to the increase of power transfer from $1 \mathrm{MW}$ to $300 \mathrm{MW}$. The maximum generator angle difference angle is $64.94^{\circ}, 71.45^{\circ}$, and $78.5^{\circ}$ for the increase of power transfer of $1 \mathrm{MW}, 150.5 \mathrm{MW}$ and $300 \mathrm{MW}$, respectively. This shows that G5 is the sensitive generator. On the other hand, the increase of the power transfer does not cause rapid changes of maximum generator rotor angle difference at generator G3. The maximum rotor angle difference of generator G3 is recorded at $74.14^{\circ}, 73.93^{\circ}$, and $73.72^{\circ}$ for $1 \mathrm{MW}, 150.5 \mathrm{MW}$, and $300 \mathrm{MW}$ of power transfer, respectively. Therefore, G3 is not a sensitive generator. Hence, a fast and accurate ATC computation could be obtained by considering the variations of maximum generator rotor angle difference only at the sensitive generator G5. 
Table 8: 39-New England bus system data.

\begin{tabular}{|c|c|c|c|c|c|c|}
\hline \multirow{2}{*}{ Bus } & \multirow{2}{*}{ Type } & \multicolumn{2}{|c|}{ Load } & \multicolumn{2}{|c|}{ Generator } & \multirow{2}{*}{ Voltage (P.U) } \\
\hline & & MW & MVAR & MW & MVAR & \\
\hline 1 & Slack & 9.2 & 4.6 & 0 & 0 & 0.9820 \\
\hline 2 & $P Q$ & 0.0 & 0.0 & 0 & 0 & 1.0 \\
\hline 3 & PQ & 322 & 2.4 & 0 & 0 & 1.0 \\
\hline 4 & PQ & 500 & 184 & 0 & 0 & 1.0 \\
\hline 5 & PQ & 0.0 & 0.0 & 0 & 0 & 1.0 \\
\hline 6 & $P Q$ & 0.0 & 0.0 & 0 & 0 & 1.0 \\
\hline 7 & PQ & 233.8 & 84 & 0 & 0 & 1.0 \\
\hline 8 & PQ & 522 & 176 & 0 & 0 & 1.0 \\
\hline 9 & $P Q$ & 0.0 & 0.0 & 0 & 0 & 1.0 \\
\hline 10 & PQ & 0.0 & 0.0 & 0 & 0 & 1.0 \\
\hline 11 & PQ & 0.0 & 0.0 & 0 & 0 & 1.0 \\
\hline 12 & $P Q$ & 7.5 & 88 & 0 & 0 & 1.0 \\
\hline 13 & PQ & 0.0 & 0.0 & 0 & 0 & 1.0 \\
\hline 14 & PQ & 0.0 & 0.0 & 0 & 0 & 1.0 \\
\hline 15 & $P Q$ & 320 & 153 & 0 & 0 & 1.0 \\
\hline 16 & $P Q$ & 329 & 32.3 & 0 & 0 & 1.0 \\
\hline 17 & PQ & 0.0 & 0.0 & 0 & 0 & 1.0 \\
\hline 18 & PQ & 158 & 30 & 0 & 0 & 1.0 \\
\hline 19 & PQ & 0.0 & 0.0 & 0 & 0 & 1.0 \\
\hline 20 & $P Q$ & 628 & 103 & 0 & 0 & 1.0 \\
\hline 21 & $P Q$ & 274 & 115 & 0 & 0 & 1.0 \\
\hline 22 & PQ & 0.0 & 0.0 & 0 & 0 & 1.0 \\
\hline 23 & PQ & 247.5 & 84.6 & 0 & 0 & 1.0 \\
\hline 24 & $P Q$ & 308.6 & -92 & 0 & 0 & 1.0 \\
\hline 25 & PQ & 224 & 47.2 & 0 & 0 & 1.0 \\
\hline 26 & PQ & 139 & 17 & 0 & 0 & 1.0 \\
\hline 27 & PQ & 281 & 75.5 & 0 & 0 & 1.0 \\
\hline 28 & $P Q$ & 206 & 27.6 & 0 & 0 & 1.0 \\
\hline 29 & PQ & 283.5 & 26.9 & 0 & 0 & 1.0 \\
\hline 30 & PV & 0.0 & 0.0 & 250 & 0 & 1.0475 \\
\hline 31 & PQ & 0.0 & 0.0 & 0 & 0 & 1.0 \\
\hline 32 & PV & 0.0 & 0.0 & 650 & 0 & 0.9831 \\
\hline 33 & PV & 0.0 & 0.0 & 632 & 0 & 0.9972 \\
\hline 34 & PV & 0.0 & 0.0 & 508 & 0 & 1.0123 \\
\hline 35 & PV & 0.0 & 0.0 & 650 & 0 & 1.0493 \\
\hline 36 & PV & 0.0 & 0.0 & 560 & 0 & 1.0635 \\
\hline 37 & PV & 0.0 & 0.0 & 540 & 0 & 1.0278 \\
\hline 38 & PV & 0.0 & 0.0 & 830 & 0 & 1.0265 \\
\hline 39 & PV & 1104 & 250 & 1000 & 0 & 1.03 \\
\hline
\end{tabular}

The maximum generator rotor angle difference of G5 is then used in (3.12) to determine the look-ahead power transfer, $P_{\text {look}}$, of $850.67 \mathrm{MW}$. The $P_{\text {look }}$ is then used in the Ralston's method to extrapolate the $P-\Delta \delta$ curve at two trajectory points and it is shown in Figure 7. By referring to Figure 7, the system is actually operating in a stable condition when $P_{\text {look }}=850.67 \mathrm{MW}$ is less than the power transfer at the second trajectory point. Therefore, the $P_{\text {look }}$ that is used in the Ralston's method is able to accurately extrapolate at the two trajectory 
Mathematical Problems in Engineering

Table 9: Transmission lines and transformers data for the 39-New England system.

\begin{tabular}{|c|c|c|c|c|c|c|c|}
\hline \multicolumn{6}{|c|}{ Line Data } & \multicolumn{2}{|c|}{ Transformer Tap } \\
\hline From Bus & To Bus & $\mathrm{R}$ & $X$ & B & Thermal Limit (MVA) & Magnitude & Angle \\
\hline 31 & 2 & 0.0035 & 0.0411 & 0.6987 & 250 & 0.000 & 0.00 \\
\hline 31 & 39 & 0.0010 & 0.0250 & 0.7500 & 250 & 0.000 & 0.00 \\
\hline 2 & 3 & 0.0013 & 0.0151 & 0.2572 & 750 & 0.000 & 0.00 \\
\hline 2 & 25 & 0.0070 & 0.0086 & 0.1460 & 500 & 0.000 & 0.00 \\
\hline 3 & 4 & 0.0013 & 0.0213 & 0.2214 & 250 & 0.000 & 0.00 \\
\hline 3 & 18 & 0.0011 & 0.0133 & 0.2138 & 100 & 0.000 & 0.00 \\
\hline 4 & 5 & 0.0008 & 0.0128 & 0.1342 & 500 & 0.000 & 0.00 \\
\hline 4 & 14 & 0.0008 & 0.0129 & 0.1382 & 500 & 0.000 & 0.00 \\
\hline 5 & 6 & 0.0002 & 0.0026 & 0.0434 & 1000 & 0.000 & 0.00 \\
\hline 5 & 8 & 0.0008 & 0.0112 & 0.1476 & 500 & 0.000 & 0.00 \\
\hline 6 & 7 & 0.0006 & 0.0092 & 0.1130 & 750 & 0.000 & 0.00 \\
\hline 6 & 11 & 0.0007 & 0.0082 & 0.1389 & 750 & 0.000 & 0.00 \\
\hline 7 & 8 & 0.0004 & 0.0046 & 0.0780 & 500 & 0.000 & 0.00 \\
\hline 8 & 9 & 0.0023 & 0.0363 & 0.3804 & 250 & 0.000 & 0.00 \\
\hline 9 & 39 & 0.0010 & 0.0250 & 1.2000 & 250 & 0.000 & 0.00 \\
\hline 10 & 11 & 0.0004 & 0.0043 & 0.0729 & 750 & 0.000 & 0.00 \\
\hline 10 & 13 & 0.0004 & 0.0043 & 0.0729 & 500 & 0.000 & 0.00 \\
\hline 13 & 14 & 0.0009 & 0.0101 & 0.1723 & 500 & 0.000 & 0.00 \\
\hline 14 & 15 & 0.0018 & 0.0217 & 0.3660 & 100 & 0.000 & 0.00 \\
\hline 15 & 16 & 0.0009 & 0.0094 & 0.1710 & 500 & 0.000 & 0.00 \\
\hline 16 & 17 & 0.0007 & 0.0089 & 0.1342 & 500 & 0.000 & 0.00 \\
\hline 16 & 19 & 0.0016 & 0.0195 & 0.3040 & 1000 & 0.000 & 0.00 \\
\hline 16 & 21 & 0.0008 & 0.0135 & 0.2548 & 500 & 0.000 & 0.00 \\
\hline 16 & 24 & 0.0003 & 0.0059 & 0.0680 & 250 & 0.000 & 0.00 \\
\hline 17 & 18 & 0.0007 & 0.0082 & 0.1319 & 500 & 0.000 & 0.00 \\
\hline 17 & 27 & 0.0013 & 0.0173 & 0.3216 & 250 & 0.000 & 0.00 \\
\hline 21 & 22 & 0.0008 & 0.0140 & 0.2565 & 1000 & 0.000 & 0.00 \\
\hline 22 & 23 & 0.0006 & 0.0096 & 0.1846 & 250 & 0.000 & 0.00 \\
\hline 23 & 24 & 0.0022 & 0.0350 & 0.3610 & 750 & 0.000 & 0.00 \\
\hline 25 & 26 & 0.0032 & 0.0323 & 0.5130 & 250 & 0.000 & 0.00 \\
\hline 26 & 27 & 0.0014 & 0.0147 & 0.2396 & 500 & 0.000 & 0.00 \\
\hline 26 & 28 & 0.0043 & 0.0474 & 0.7802 & 250 & 0.000 & 0.00 \\
\hline 26 & 29 & 0.0057 & 0.0625 & 1.0290 & 500 & 0.000 & 0.00 \\
\hline 28 & 29 & 0.0014 & 0.0151 & 0.2490 & 500 & 0.000 & 0.00 \\
\hline 12 & 11 & 0.0016 & 0.0435 & 0.0000 & 250 & 1.006 & 0.00 \\
\hline 12 & 13 & 0.0016 & 0.0435 & 0.0000 & 100 & 1.006 & 0.00 \\
\hline 6 & 1 & 0.0000 & 0.0250 & 0.0000 & 1000 & 1.070 & 0.00 \\
\hline 10 & 32 & 0.0000 & 0.0200 & 0.0000 & 1000 & 1.070 & 0.00 \\
\hline 19 & 33 & 0.0007 & 0.0142 & 0.0000 & 1000 & 1.070 & 0.00 \\
\hline 20 & 34 & 0.0009 & 0.0180 & 0.0000 & 1000 & 1.009 & 0.00 \\
\hline 22 & 35 & 0.0000 & 0.0143 & 0.0000 & 1000 & 1.025 & 0.00 \\
\hline 23 & 36 & 0.0005 & 0.0272 & 0.0000 & 1000 & 1.000 & 0.00 \\
\hline 25 & 37 & 0.0006 & 0.0232 & 0.0000 & 1000 & 1.025 & 0.00 \\
\hline 2 & 30 & 0.0000 & 0.0181 & 0.0000 & 500 & 1.025 & 0.00 \\
\hline 29 & 38 & 0.0008 & 0.0156 & 0.0000 & 1000 & 1.025 & 0.00 \\
\hline 19 & 20 & 0.0007 & 0.0138 & 0.0000 & 250 & 1.060 & 0.00 \\
\hline
\end{tabular}




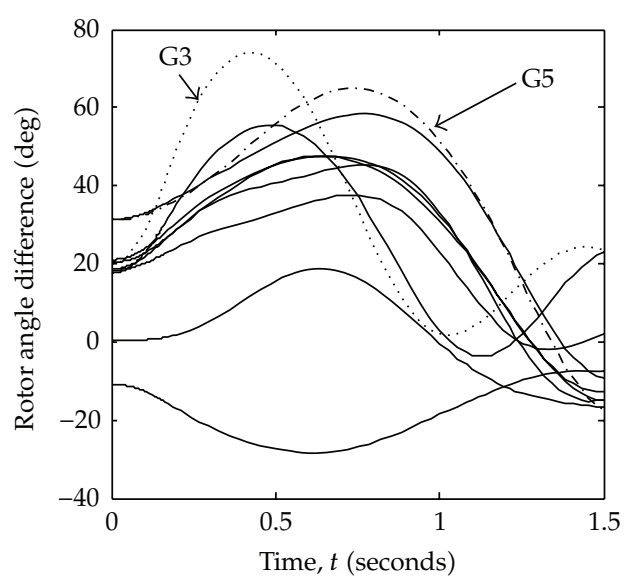

(a) Power transfer of $1 \mathrm{MW}$

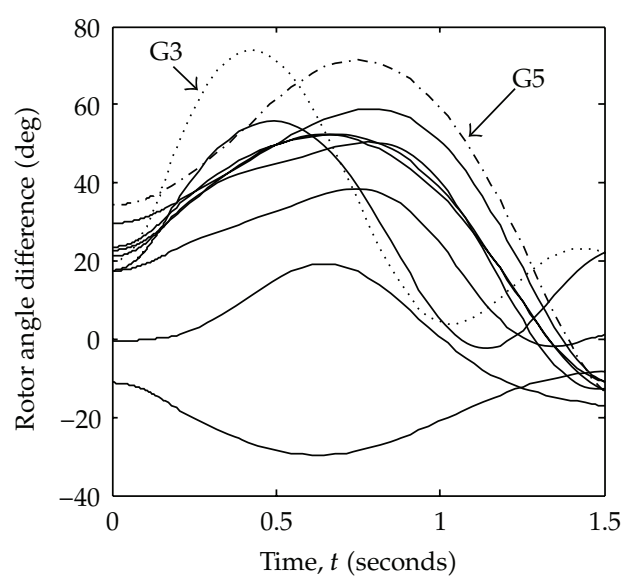

(b) Power transfer of $150.5 \mathrm{MW}$

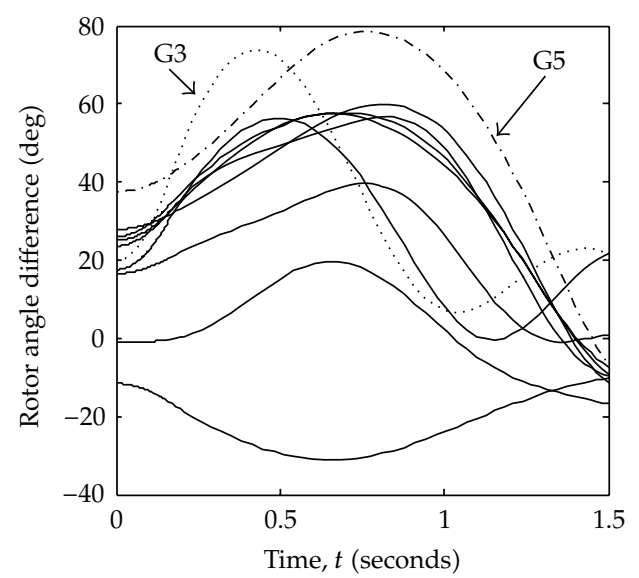

(c) Power transfer of $300 \mathrm{MW}$

Figure 6: The variations of maximum rotor angle difference for every generator at the; (a) power transfer of $1 \mathrm{MW}$; (b) power transfer of 150.5 MW; and (c) power transfer of $300 \mathrm{MW}$.

points for optimum or accurate estimation of ATC. In Figure 7, the Ralston's method performs four incremental steps $(n)$ of power transfer and it is reasonable enough to provide fast and accurate approximation of the two trajectory points. The two trajectory points are located at the power transfer of $850.67 \mathrm{MW}$ and $1275.50 \mathrm{MW}$. It is believed that the actual value of ATC that causes the violation of generator rotor angle difference limit falls within these two points of trajectory and it can be observed in Figure 7.

Then, the AC power flow solution is performed at four incremental steps of power transfer, which are 850.67 MW, 992.28 MW, 1133.89 MW and 1275.50 MW. The four power transfers are obtained by equal division between the range of ATC $=850.67 \mathrm{MW}$ and ATC $=$ 1275.50 MW located at the two trajectory points. Figure 8 shows the variations of maximum generator rotor angle difference for the increase of four power transfers. It is obvious that the sensitive generator is still referring to G5. This is due to the fact that the increase of power transfers from $850.67 \mathrm{MW}$ to $1275.50 \mathrm{MW}$ causing the rapid changes of maximum generator 


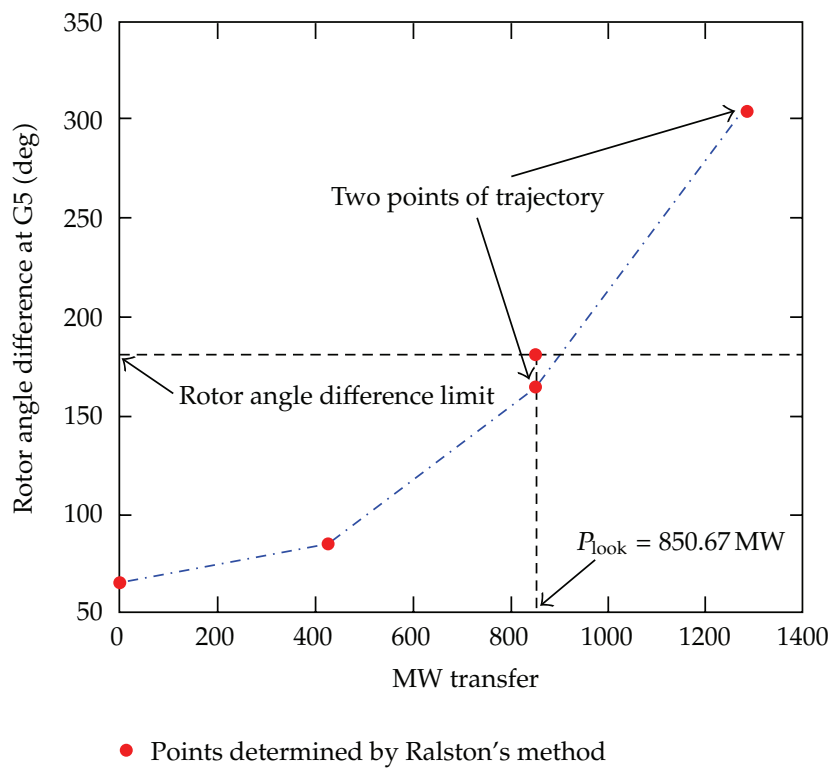

Figure 7: The two trajectory points obtained by using the Ralston's method.

rotor angle difference at G5. The maximum generator angle difference angle is $164.82^{\circ}$, $282.98^{\circ}, 396.69^{\circ}$, and $529.41^{\circ}$ for the increase of power transfer of $850.67 \mathrm{MW}, 992.28 \mathrm{MW}$, $1133.89 \mathrm{MW}$, and $1275.50 \mathrm{MW}$, respectively.

Finally, the increase of four power transfers and the four maximum rotor angle differences are used in the cubic-spline interpolation technique to fit the $P-\Delta \delta$ curve between the two trajectory points of the sensitive generator G5. In Figure 9, it is shown that the cubicspline interpolation technique traces the $P-\Delta \delta$ curve based on the four points of power transfer and maximum generator rotor angle difference. A point is noted where the generator rotor angle difference limit of $180^{\circ}$ intersects the $P-\Delta \delta$ curve. This point yields an actual ATC value of $870 \mathrm{MW}$.

\subsection{Results of Area-To-Area ATC due to Transient Stability Limit: Case Study of 39-New England Bus System}

Table 5 represents the results of ATC obtained only by considering the violation of generator rotor angle difference limit. This is to prove that the proposed method is also robust in determining the ATC based on the violation of transient stability limit. Whereby, the rotor angle difference limit is referred to as the transient stability limit. In this case study, it is assumed that a three-phase fault happened at bus 10. Therefore, the computation of ATCsbased transient stability limit is performed by considering the tripping of line 10-13 for clearing the fault. The fault critical clearing time of $t=0.15$ second is specified for the tripping at line 10-13. The transient response of generator rotor angle difference is monitored for 1.5 seconds in the case study of ATC that takes into account the transient stability limit. The proposed method gives the ATC value of $448 \mathrm{MW}$ for the interarea transfer from area 1 to area 2 , and this is referring to the violation of the rotor angle difference limit of generator G3 which is located at bus 32 . The proposed method accurately determines the ATC that is relatively 


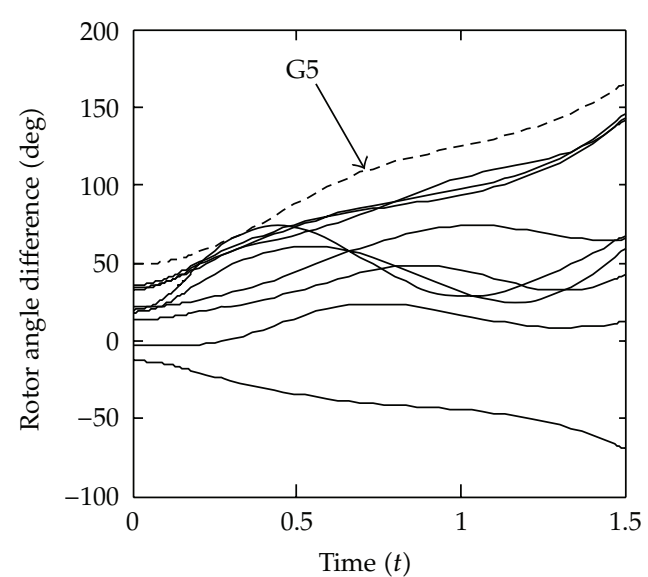

(a) Power transfer of $850.67 \mathrm{MW}$

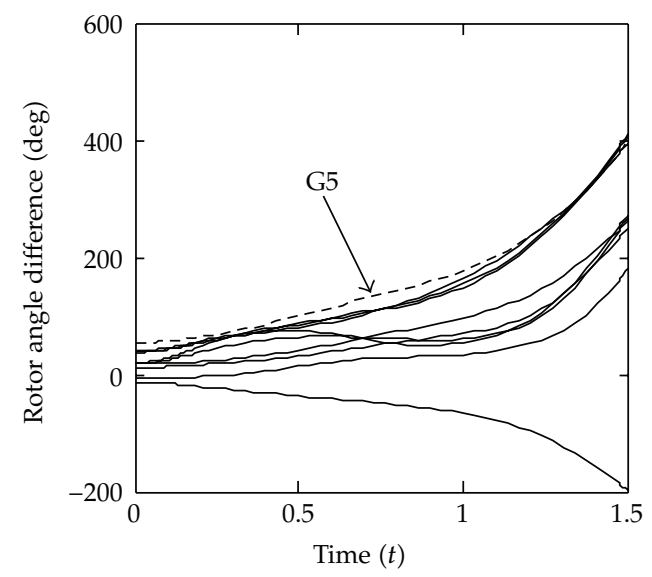

(c) Power transfer of $1133.89 \mathrm{MW}$

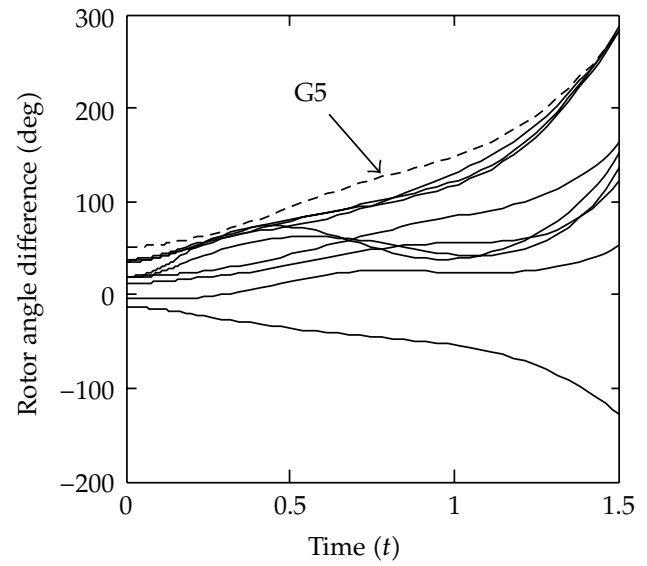

(b) Power transfer of $992.28 \mathrm{MW}$

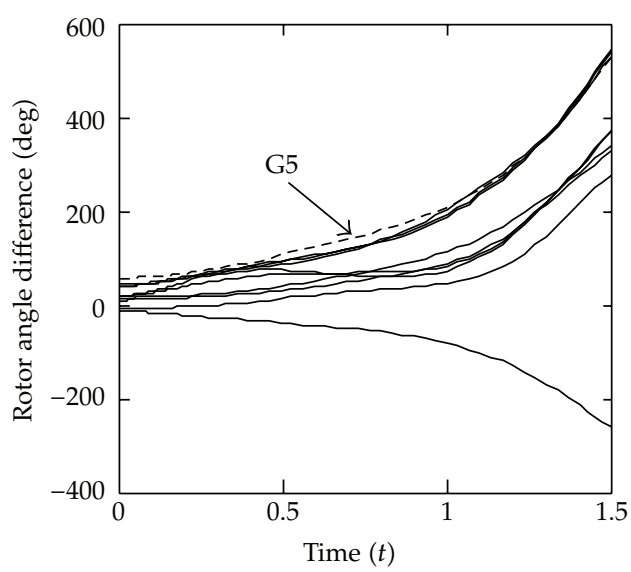

(d) Power transfer of $1275.50 \mathrm{MW}$

Figure 8: The variations of maximum rotor angle difference based on the; (a) power transfer of 850.67 MW; (b) power transfer of 992.28 MW; (c) power transfer of 1133.89 MW; and (d) power transfer of 1275.50 MW.

similar to the ATC value of $449 \mathrm{MW}$ determined by the recursive AC power flow method. This is similar to the other cases of interarea power transfer. By comparing the ATC values obtained in Tables 3 and 5, it can be concluded that the ATCs are actually obtained due to the violation of transmission line limit. It also shows that the violation of generator rotor angle difference limit gives higher value of ATC in comparison to the violation of transmission line limit. However, in a real system operating condition, the first violation may occur at the transmission line limit that yields the amount of power transfer. On the other hand, it is noted that the proposed method performs a fast ATC computation as compared to the recursive AC power flow method. The results have shown that the proposed method is able to provide fast and accurate value of ATC although it refers to the limit of transient stability. The results of point-to-point ATC are not shown in this section. This is because any further increase of power transfer between buses does not violate the limit of generator rotor angle difference. This is due to the fact that any increase of power transfer from a particular generator does not adversely affect the synchronism of generating system. 


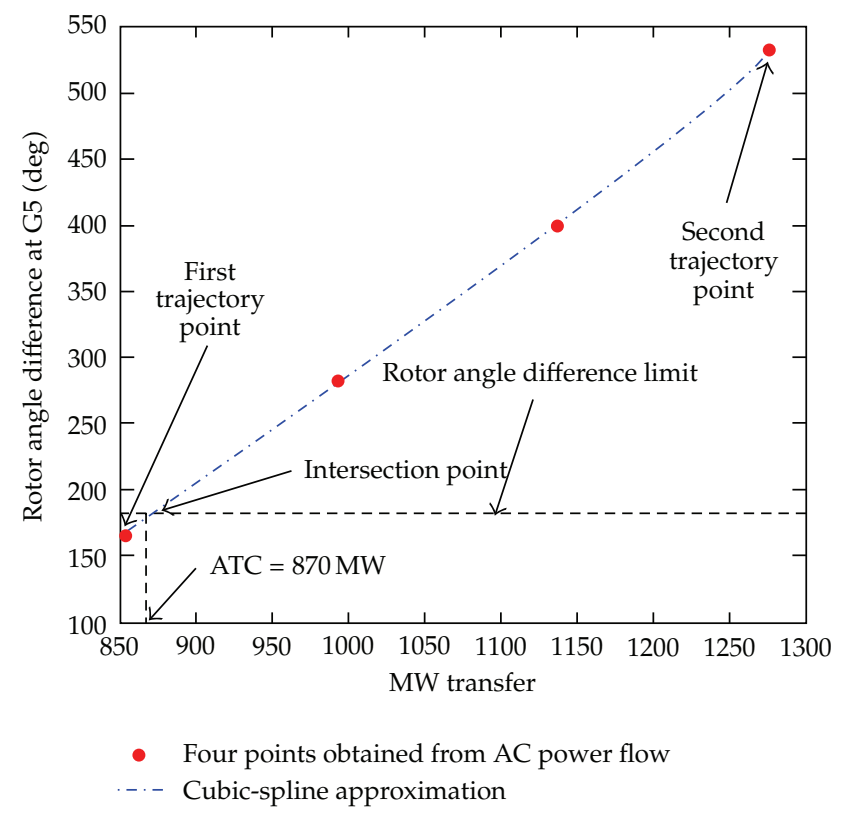

Figure 9: The actual value of ATC obtained at two trajectory points.

\section{Conclusion}

This paper presents a new approach that is used to evaluate the area-to-area and point-topoint ATCs. The proposed method is based on the Ralston method incorporating with cubicspline interpolation technique. The Ralston's method is used to determine the two trajectory points of voltage magnitude, power flow, and maximum generator rotor angle difference. Then, the cubic-spline interpolation technique is used to trace the $P-V, P-S$, or $P-\Delta \delta$ curves between the two trajectory points. The curve fitting procedure is performed to reduce the time in ATC computation. By referring to the $P-V, P-S$, or $P-\Delta \delta$ curves between the two trajectory points, the ATC is determined at the intersecting point of voltage, MVA power flow or generator rotor angle difference limits. The effectiveness of the proposed method in determining the ATC is verified on a case study of 2737-bus Polish and 39-New England bus power systems. It is proven that the Ralston's method incorporating with cubic-spline interpolation technique is a fast and accurate method for ATC evaluation as compared to the ATC method using recursive AC power flow method. The proposed method is an effective way to speed up the ATC computation. The proposed method is useful for the utilities in a deregulated electricity market in which the ATCs are required to be posted in a real-time market signal so that all transmission users have the same chance to access transmission information.

\section{References}

[1] G. Hamoud, "Assessment of available transfer capability of transmission systems," IEEE Transactions on Power Systems, vol. 15, no. 1, pp. 27-32, 2000.

[2] North America Electric Reliability Council (NERC), "Available transfer capability definitions and determination," June 1996, http:/ /www.nerc.com/docs/docs/pubs/atcfinal.pdf . 
[3] P. W. Sauer, "Technical challenges of computing available transfer capability (ATC) in electric power systems," in Proceedings of the 30th Annual Hawaii International Conference on System Sciences, vol. 5, pp. 589-593, Wailea, Hawaii, USA, 1997.

[4] M. Shaaban, Y. Ni, H. Dai, and F. F. Wu, "Considerations in calculating total transfer capability," in Proceedings of the International Conference Power System Technology (POWERCON '98), vol. 2, pp. 13561360, 1998.

[5] M. Shaaban, Y. Ni, and F. F. Wu, "Transfer capability computations in deregulated power systems," in Proceedings of the 33rd Annual Hawaii International Conference System Sciences, pp. 1-5, 2000.

[6] R. D. Christie, B. F. Wollenberg, and I. Wangensteen, "Transmission management in the deregulated environment," Proceedings of the IEEE, vol. 88, no. 2, pp. 170-195, 2000.

[7] M. M. Othman, A. Mohamed, and A. Hussain, "Fast evaluation of available transfer capability using cubic-spline interpolation technique," Electric Power Systems Research, vol. 73, no. 3, pp. 335-342, 2005.

[8] M. M. Othman, A. Mohamed, and A. Hussain, "A neural network based ATC assessment incorporating novel feature selection and extraction methods," Electric Power Components and Systems, vol. 32, no. 11, pp. 1121-1136, 2004.

[9] G. C. Ejebe, G. D. Irisarri, S. Mokhtari, O. Obadina, P. Ristanovic, and J. Tong, "Methods for contingency screening and ranking for voltage stability analysis of power systems," IEEE Transactions on Power Systems, vol. 11, no. 1, pp. 350-356, 1996.

[10] H.-D. Chiang, C.-S. Wang, and A. J. Flueck, "Look-ahead voltage and load margin contingency selection functions for large-scale power systems," IEEE Transactions on Power Systems, vol. 12, no. 1, pp. 173-180, 1997.

[11] O. B. Fosso, N. Flatabo, B. Hakavik, and A. T. Holen, "Comparison of methods for calculation of margins to voltage instability," in Proceedings of the Athens Power Technology Conference, Greece, 1993.

[12] S. C. Chapra and R. P. Canale, Numerical Methods for Engineers: With Software and Programming Application, McGraw-Hill, New York, NY, USA, 4th edition, 2003.

[13] R. D. Zimmerman and D. Gan, MATPOWER: version 3.2. School of Electrical Engineering, Cornell University, 2007.

[14] M. M. Othman, A. Mohamed, and A. Hussain, "Available transfer capability assessment using evolutionary programming based capacity benefit margin," International Journal of Electrical Power and Energy Systems, vol. 28, no. 3, pp. 166-176, 2006.

[15] M. M. Othman, A. Mohamed, and A. Hussain, "Determination of transmission reliability margin using parametric bootstrap technique," IEEE Transactions on Power Systems, vol. 23, no. 4, pp. 16891700, 2008.

[16] I. Dobson, S. Greene, and R. Rajaraman, "Electric power transfer capability: concepts, applications, sensitivity and uncertainty," http://www.pserc.cornell.edu/tcc/info.html .

[17] H. Saadat, Power System Analysis, McGraw-Hill, New York, NY, USA, 2nd edition, 2004.

[18] Y. Xia, K. W. Chan, M. Liu, and J. Wu, "Calculation of available transfer capability with transient stability constraints," in Proceedings of the IEEE International Conference on Electric Utility Deregulation, Restructuring and Power Technologies (DRPT '04), vol. 1, pp. 128-132, Hong Kong, 2004.

[19] Y. Yuan, J. Kubokawa, T. Nagata, and H. Sasaki, “A solution of dynamic available transfer capability by means of stability constrained optimal power flow," in Proceedings of the IEEE Bologna Power Technology Conference, Italy, 2003.

[20] M. H. Haque, "Novel method of finding the first swing stability margin of a power system from time domain simulation," IEE Proceedings: Generation, Transmission and Distribution, vol. 143, no. 5, pp. 413-419, 1996.

[21] Y.-K. Wu, "A novel algorithm for ATC calculations and applications in deregulated electricity markets," International Journal of Electrical Power and Energy Systems, vol. 29, no. 10, pp. 810-821, 2007.

[22] M. El-Hawary, Electrical Power Systems: Design and Analysis, Power Systems Engineering Series, WileyInterscience, IEEE Press, New York, NY, USA, 1995.

[23] Y. Ou and C. Singh, "Assessment of available transfer capability and margins," IEEE Transactions on Power Systems, vol. 17, no. 2, pp. 463-468, 2002.

[24] M. A. Pai, Energy function analysis for power system stability, Kluwer Academic Publishers, Boston, 1989.

[25] C. K. Babulal and P. S. Kannan, "A novel approach for ATC computation in deregulated environment," Journal of Electrical Systems, pp. 146-161, 2006. 
[26] P. Kundur, Power System Stability and Control, McGraw-Hill, New York, NY, USA, 1994.

[27] M. Pavella and P. G. Murthy, Transient Stability of Power Systems: Theory and Practice, John Wiley \& Sons, New York, NY, USA, 1994.

[28] M. H. Haque and A. H. M. A. Rahim, "Determination of first swing stability limit of multimachine power systems through Taylor series expansions," IEE Proceedings, vol. 136, pp. 373-379, 1989. 


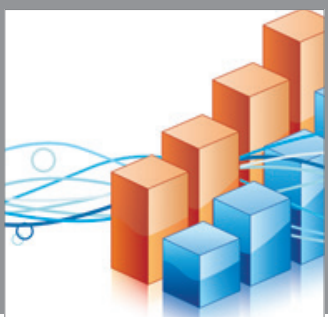

Advances in

Operations Research

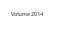

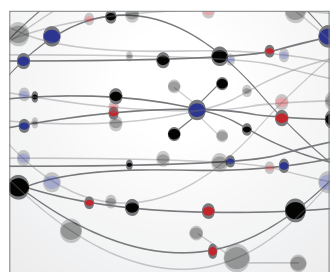

\section{The Scientific} World Journal
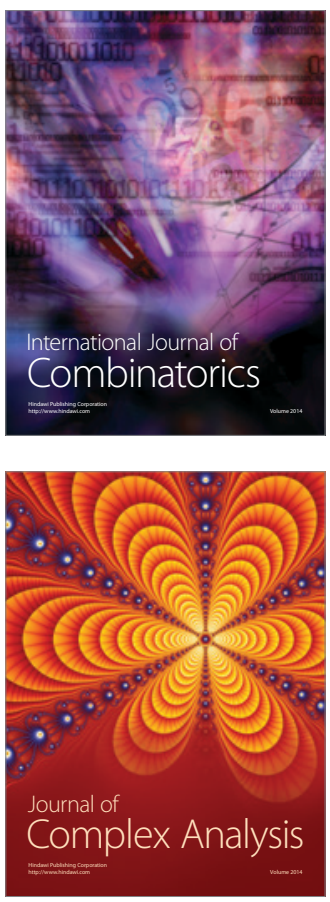

International Journal of

Mathematics and

Mathematical

Sciences
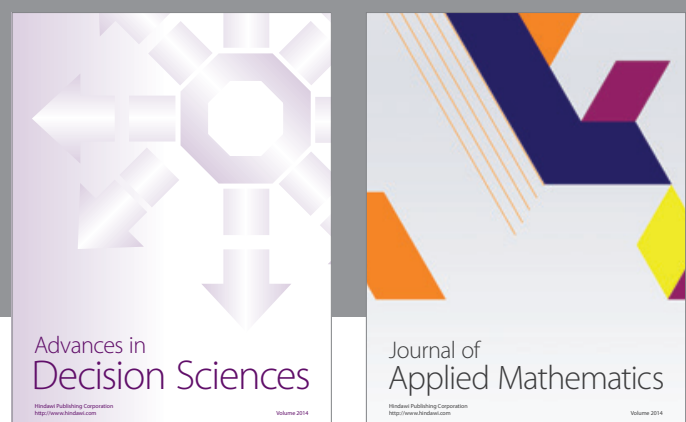

Journal of

Applied Mathematics
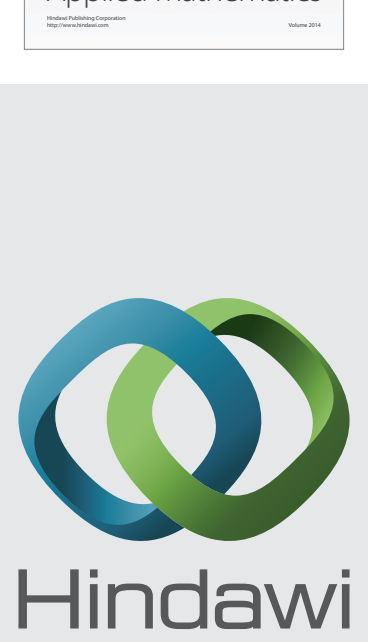

Submit your manuscripts at http://www.hindawi.com
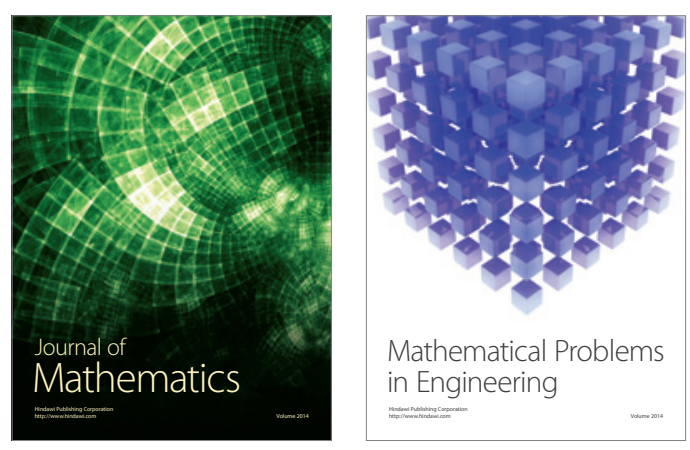

Mathematical Problems in Engineering
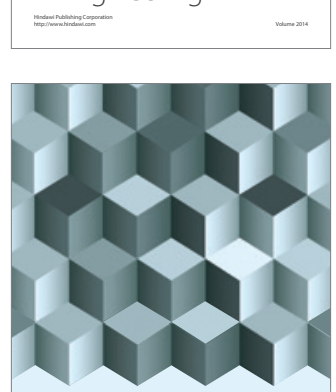

Journal of

Function Spaces
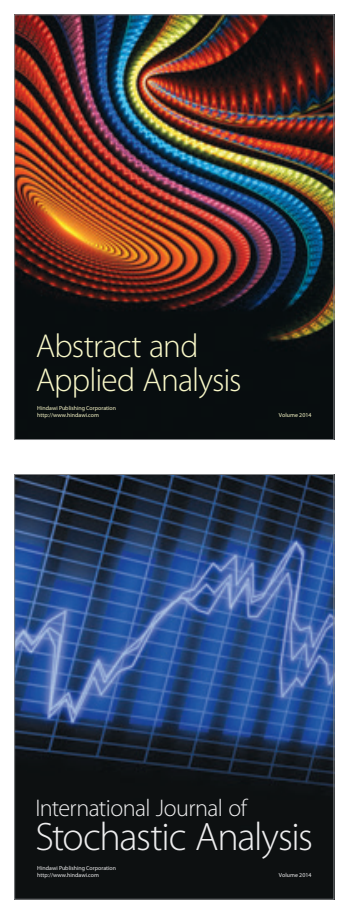

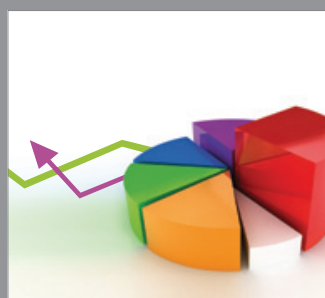

ournal of

Probability and Statistics

Promensencen
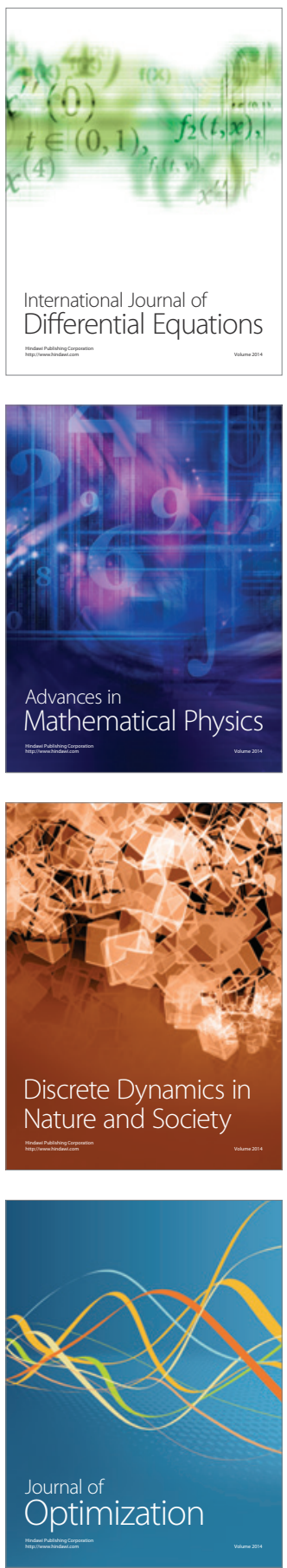